\title{
1 PRESENILIN 1 mutations causing early-onset familial Alzheimer's \\ 2 disease or familial acne inversa differ in their effects on genes \\ 3 facilitating energy metabolism and signal transduction
}

4 Karissa Barthelson ${ }^{\mathrm{a}^{*}}$, Yang Dong $^{\mathrm{a}}$, Morgan Newman ${ }^{\mathrm{a}}$ and Michael Lardelli ${ }^{\mathrm{a}}$

5 a Alzheimer's Disease Genetics Laboratory, School of Biological Sciences, University of

6 Adelaide, North Terrace, Adelaide, SA 5005, Australia

$7 \quad *$ Corresponding author

8 Complete correspondence address: Room 1.24, Molecular Life Sciences Building. North

9 Terrace Campus. The University of Adelaide, SA 5005, Australia.

10 Telephone: 83134863

11 Email: karissa.barthelson@adelaide.edu.au

12 Running title: RNA-seq analysis of psen1 mutations 
Background: The most common cause of early-onset familial Alzheimer's disease (EOfAD) is mutations in PRESENILIN 1 (PSEN1) allowing production of mRNAs encoding full-length, but mutant, proteins. In contrast, a single known frameshift mutation in PSEN1 causes familial acne inversa (fAI) without EOfAD. The molecular consequences of heterozygosity for these mutation types, and how they cause completely different diseases, remains largely unexplored.

Objective: To analyse brain transcriptomes of young adult zebrafish to identify similarities and differences in the effects of heterozygosity for psen1 mutations causing EOfAD or fAI.

Methods: RNA sequencing was performed on mRNA isolated from the brains of a single family of 6-month-old zebrafish siblings either wild type or possessing a single, heterozygous EOfAD-like or fAI-like mutation in their endogenous psen1 gene.

Results: Both mutations downregulate genes encoding ribosomal subunits, and upregulate genes involved in inflammation. Genes involved in energy metabolism appeared significantly affected only by the EOfAD-like mutation, while genes involved in Notch, Wnt and neurotrophin signalling pathways appeared significantly affected only by the fAl-like mutation. However, investigation of direct transcriptional targets of Notch signalling revealed possible increases in $\gamma$-secretase activity due to heterozygosity for either psen 1 mutation. Transcriptional adaptation due to the fAl-like frameshift mutation was evident. 
34 Conclusion: We observed both similar and contrasting effects on brain transcriptomes of the

35 heterozygous EOfAD-like and fAl-like mutations. The contrasting effects may illuminate how

36 these mutation types cause distinct diseases.

37 KEY WORDS

38 Presenilin 1, RNA-seq, zebrafish, gamma-secretase, Alzheimer's disease, acne inversa

39

40 
42 Cases of Alzheimer's disease (AD) can be classified by age of onset and mode of inheritance.

43 Dominant mutations in a small number of genes cause AD with an age of onset younger than

4465 years (early onset familial AD, EOfAD). On a population basis, around $60 \%$ of the

45 mutations causing EOfAD occur in one gene, PRESENILIN 1 (PSEN1) [1-4].

PSEN1 encodes a multi-pass transmembrane protein resident in the endoplasmic reticulum, plasma membrane, endolysosomal pathway and other membranes $[5,6]$. It has nine recognised transmembrane domains [7]. A tenth transmembrane domain may exist when PSEN1 protein is in its holoprotein state [7], before it undergoes autocatalytic endoproteolysis to form the active catalytic core of $\gamma$-secretase [8], an enzyme complex consisting of PSEN1 (or PSEN2), and the proteins NCSTN, PSENEN, and APH1A (or APH1B) [9, 52 10].

53 As a locus for genetic disease, PSEN1 is truly remarkable both for the number of mutations

54 found there, and the variety of diseases these mutations cause. Mutations have been found associated with Pick's disease [11], dilated cardiomyopathy [12] and acne inversa [13]. However, over 300 mutations of PSEN1 are known to cause EOfAD

57 (www.alzforum.org/mutations/psen-1). In total, these mutations affect 161 codons of the gene. Remarkably, the mutations are widely distributed in the PSEN1 coding sequence, but are particularly common in the transmembrane domains. Only three regions of the PSEN1 protein are mostly devoid of EOfAD mutations: upstream of the first transmembrane 
domain; a large part of the "cytosolic loop domain" (cytosolic loop 3); and the last two thirds of the $9^{\text {th }}$ transmembrane domain together with the lumenal C-terminus (see Figure 1).

The most common outcome of mutation of a protein sequence is either no effect or a detrimental effect on the protein's evolved activity. Only rarely are mutations selectively advantageous so that they enhance organismal survival and reproduction. The very large number of EOfAD-causative mutations in PSEN1 and their wide distribution in the protein coding sequence is consistent with a loss-of-function. However, this cannot be a simple loss of $\gamma$-secretase activity, as EOfAD-causative mutations have never been found in the genes encoding the other components of $\gamma$-secretase complexes (other than less frequent mutations in the PSEN1 homologous gene, PSEN2, reviewed in [14]). Also, an in vitro analysis of 138 EOfAD mutations of PSEN1 published in 2017 by Sun et al. [15] found that approximately $10 \%$ of these mutations actually increased $\gamma$-secretase activity. mutations of PSEN1 cause disease is that these act through "qualitative changes" to $\gamma$ secretase cleavage of the AMYLOID $\beta$ A4 PRECURSOR PROTEIN (A $\beta P P)$ to alter the length distribution of the AMYLOID $\beta$ (A $\beta$ ) peptides derived from it [16]. However, the comprehensive study of Sun et al. revealed no consistency in the effects of PSEN1 EOfAD mutations on $A \beta$ length distribution. The single consistent characteristic of all EOfAD mutations in both PSEN1 and PSEN2 is that these permit production of transcripts with coding sequences containing in-frame mutations, but terminated by the wild type stop codons (i.e. they still permit production of a full length protein). This phenomenon was first noted by De Strooper in 2007 [17] and described in detail by us in 2016 (the "reading frame 
preservation rule" [18]). The universality of this rule, and that it reflects a critical feature of

the EOfAD-causative mechanism of PSEN1 mutations, is shown by the fact that the

P242LfsX11 frameshift mutation of PSEN1 (hereafter referred to as P242fs) causes a

Understanding the role of PSENs and their mutations is complicated by the partial functional redundancy shared by PSEN1 and PSEN2 and their complex molecular biology. For example, the PSEN1 holoprotein has been shown to have $\gamma$-secretase-independent activities required for normal lysosomal acidification [20], can form multimers [21-24], and may interact with the HIF1 $\alpha$ protein [25-27] that is critical both for responses to hypoxia and for iron homeostasis (reviewed in [28]). Additionally, within $\gamma$-secretase complexes, the PSENs act to cleave at least 149 different substrates [29]. To simplify analysis, most previous investigation of PSEN activity has involved inactivation (knock-out) of PSEN1 and/or PSEN2 in cells or expression of wild type forms). Forced expression of PSEN genes is also usually at nonphysiological levels which has unexpected regulatory feedback effects [30]. In humans, investigating PSEN's role in AD at the molecular level is restricted to post-mortem brain tissues. However, these show substantially different patterns of gene expression compared 
to the brains of people with mild cognitive impairment (MCI) or age-matched healthy controls [31]. Since AD is thought to take decades to develop [32], we must understand the pathological effects of EOfAD mutations in young adult brains if we wish to identify preventative treatments. For this reason, we must model EOfAD mutations in animals.

110 The overwhelming majority of animal modelling of AD has utilised transgenic models

111 favoured for their apparent, partial reproduction of $A \beta$ histopathology and easily discernible

112 cognitive disabilities. However, the relationship between $A \beta$ histopathology and cognitive change in these models is questionable [33]. Additionally, the most detailed form of molecular phenotyping currently available, transcriptome analysis, shows little consistency between the disturbed brain gene transcription of various transgenic models and limited concordance between them and human sporadic AD brain transcriptomes [34]. "Knock-in"

117 mouse models of single EOfAD mutations (e.g. [35, 36]) make the fewest assumptions regarding the pathological mechanism(s) of $A D$ and most closely replicate the human EOfAD genetic state (i.e. incorporating a single, dominant, endogenous mutation in the heterozygous state). However, the brain transcriptomes of these mice have never been analysed, and interest in them waned due to their lack of $A \beta$ histopathology and mild cognitive effects.

Analysis of mouse brain transcriptomes is complicated by strong effects on gene expression

124 of sex [37, 38] and, potentially, litter-of-origin (i.e. due to environmental and genotypic variation) (K. Barthelson, unpublished results). In contrast, zebrafish brain transcriptomes

126 show only subtle influences of sex, and very large numbers of siblings can be generated from 127 single mating event, alleviating potential litter-of-origin issues [39-43]. In 2014, our 
laboratory began a program of creating knock-in models of EOfAD-like (and non-EOfAD-like)

mutations in the zebrafish genes orthologous to PSEN1, PSEN2, and SORL1. In 2019 we

began publishing the results of transcriptome analyses of the young adult brains of these fish (and differentiate them from the non-EOfAD-like mutations). equivalent of any human EOfAD-causative mutation. Consequently, in this study we aimed to generate an additional, exactly equivalent, model of a human PSEN1 EOfAD mutation. For technical reasons, the T428 codon of zebrafish psen1 (equivalent to the T440 codon of human PSEN1) was predicted to be readily targetable using CRISPR-Cas9 technology, and we

141 subsequently deleted this codon in the zebrafish gene. This generated a zebrafish model of the human EOfAD mutation PSEN1 ${ }^{\text {T440del }}$ [47]. This mutation was identified in a Japanese man classified as displaying a mixed dementia phenotype (variant AD with spastic paraparesis, Parkinson's disease and dementia with Lewy bodies). Also, to understand how reading-frame preserving and frameshift mutations can cause completely different diseases we generated a frameshift mutation in zebrafish $p \operatorname{sen} 1, \operatorname{psen} 1^{\text {W233fs }}$, very similar to the fAlcausative P242fs mutation of human PSEN1. We then performed an RNA-seq analysis with

148 high read depth and large sample numbers to compare the brain transcriptomes of fish from 149 a single family of young adult siblings heterozygous for either mutation or wild type. We 150 observed subtle, and mostly distinct, effects of the two mutations. In particular, changes in 
the fAl-like brain transcriptomes implied significant effects on Notch, Wnt, neurotrophin, and Toll-like receptor signalling, while changes in the EOfAD-like brain transcriptomes implied effects on oxidative phosphorylation similar to those previously seen for EOfAD-like mutations in psen1 [45], psen2 [40, 43], and sorl1 [39, 41].

157 All zebrafish (Tübingen strain) used in this study were maintained in a recirculating water system on a 14 hour light/10 hour dark cycle, fed dry food in the morning and live brine shrimp in the afternoon. All zebrafish work was conducted under the auspices of the Animal Ethics Committee (permit numbers S-2017-089 and S-2017-073) and the Institutional Biosafety Committee of the University of Adelaide.

To mutate zebrafish psen1, we used the Alt-R ${ }^{\circledR}$ CRISPR-Cas9 system (Integrated DNA of psen1, we used a custom-designed crRNA recognising the sequence $5^{\prime}$ CTCCCCATCTCCATAACCTT 3' and a PAM of CGG. For the W233fs mutation (fAl-like), the crRNA was designed to recognise the sequence 5' GATGAGCCATGCGGTCCACT 3' in exon 6 of psen1, with a PAM sequence of CGG. We aimed to generate exact equivalents of the human P242fs mutation causing fAl, and the T440del mutation causing EOfAD by homology 
171 described in [48] (synthesised by Biomatik, Kitchener, Ontario, Canada). For the T440del

172 mutation, we used an antisense, asymmetric single-stranded oligonucleotide with

173 phosphorothioate modifications (synthesised by Merck, Kenilworth, NJ, USA) as described in

174 [49] (HDR template DNA sequences are given in Supplementary File 1.)

175 Each crRNA was annealed with an equal amount of Alt-R ${ }^{\circledR}$ CRISPR-Cas9 tracrRNA (IDT) in

176 nuclease free duplex buffer (IDT) by heating at $95^{\circ} \mathrm{C}$ for 5 minutes, then allowed to cool to

177 room temperature, giving sgRNA solutions of $33 \mu \mathrm{M}$ (assuming complete heteroduplex

178 formation of the RNA molecules). Then, $1 \mu \mathrm{L}$ of the sgRNA solution was incubated with $1 \mu \mathrm{L}$

179 of Alt-R ${ }^{\circledast}$ S.p.Cas9 Nuclease $3 N$ LS (IDT) at $64 \mu \mathrm{M}$ at $37^{\circ} \mathrm{C}$ for 10 minutes to form

180 ribonucleoprotein (RNP) complexes. The final concentration for the linear sSODN for the

181 T428del mutation was $1 \mu \mathrm{M}$, and the final concentration of the plasmid DNA for the W233fs

182 mutation was $25 \mathrm{ng} / \mu \mathrm{L}$. Approximately 2-5 nL of RNP complexes in solution with the

183 respective template DNAs were injected into Tübingen strain zebrafish embryos at the one

184 cell stage. The procedures followed for testing of the mutagenesis efficiencies of CRISPR-

185 Cas9 systems using allele-specific polymerase chain reactions and T7 endonuclease I assays,

186 and the breeding strategy to isolate the mutations of interest, are described in $[41,50]$. 
bioRxiv preprint doi: https://doi.org/10.1101/2021.01.26.428321; this version posted February 9, 2021. The copyright holder for this preprint (which was not certified by peer review) is the author/funder, who has granted bioRxiv a license to display the preprint in perpetuity. It is made available under aCC-BY-NC 4.0 International license.

A

B

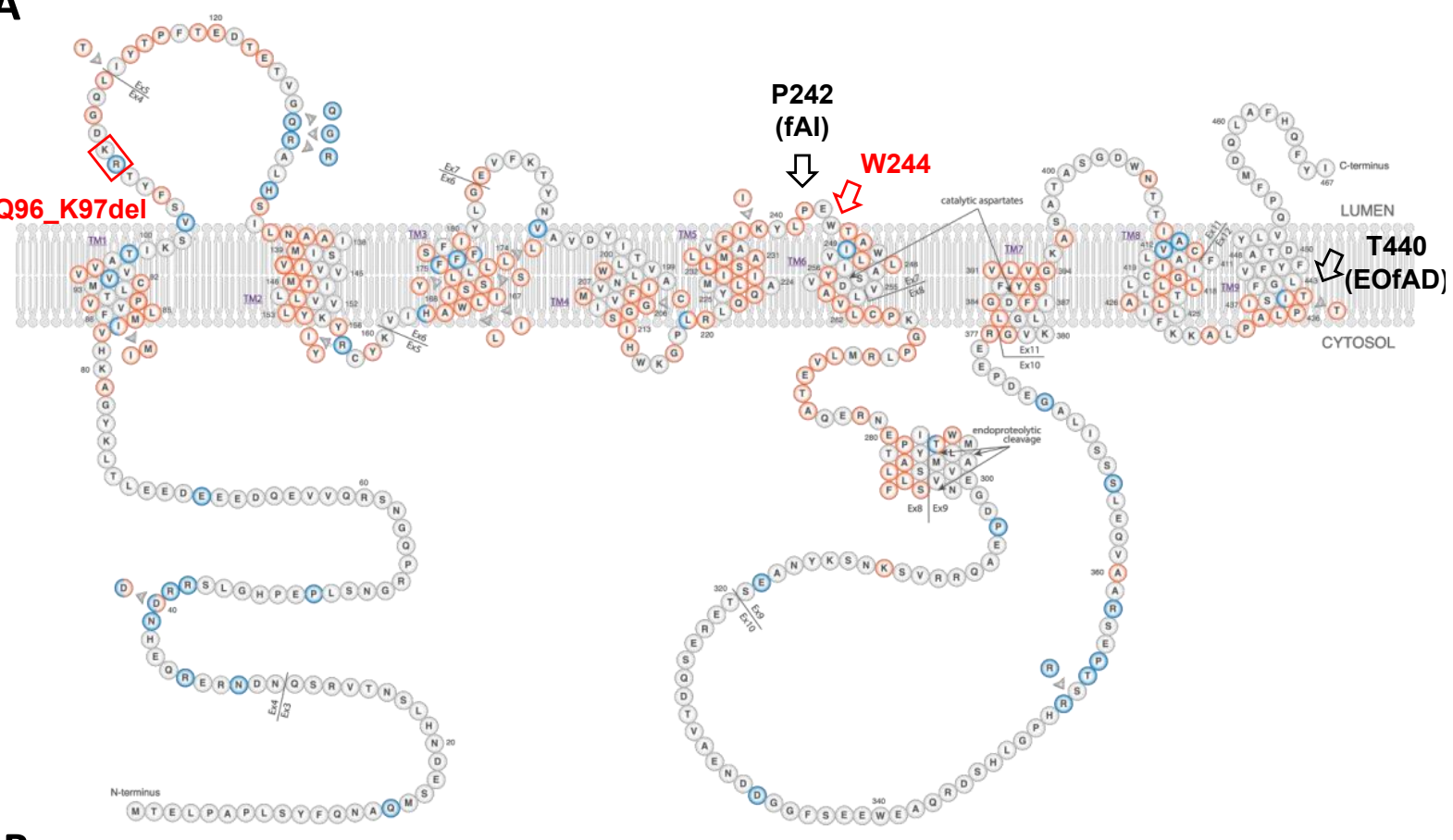

fAl-

like/+

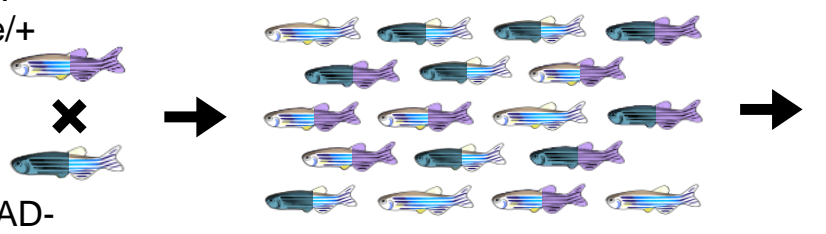

like/+

fAl-

like/+

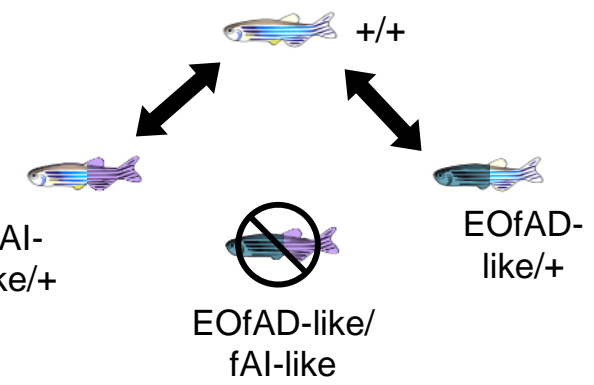


bioRxiv preprint doi: https://doi.org/10.1101/2021.01.26.428321; this version posted February $9,2021$. The copyright holder for this preprint (which was not certified by peer review) is the author/funder, who has granted bioRxiv a license to display the preprint in perpetuity. It is made available under aCC-BY-NC 4.0 International license.

189

190

191

192

193

194

195

196

197

198

199

200

201

202

203

204

205

206

207

208

209

210

211

212

213

214

Figure 1: Experimental design. A Schematic of the human PSEN1 protein adapted from

https://www.alzforum.org/mutations/psen-1 with permission from FBRI LLC (Copyright @ 1996-2020 FBRI LLC. All Rights Reserved. Version 3.3 - 2020). Amino acid residues are colour-coded as to whether they are pathogenic for Alzheimer's disease (red) or their pathogenicity is unclear (blue). The human mutation sites (P242 (fAl) and T440 (EOfAD) are indicated by black arrows. The site of the zebrafish W233fs-equivalent codon (W244) is shown by the red arrow. Note that the human T440 codon is equivalent to the zebrafish T428 codon. The residues equivalent to those deleted in the Q96_K97del mutation of zebrafish psen 1 analysed previously are indicated by a red box. B A fish heterozygous for the W233fs mutation (fAI-like/+) was mated with a fish heterozygous for the T428del mutation (EOfAD-like/+). The resulting family of fish contain genotypes fAI-like/+, EOfAD-like/+, EOfAD-like/fAl-like and their wild type siblings. The pairwise comparisons performed in the RNA-seq experiment are depicted. Since the EOfAD-like/fAI-like genotype is not representative of any human disease, it was not analysed. See online version for colour.

We performed RNA-seq on a family of zebrafish as described in Figure 1. Total RNA (with genomic DNA depleted by DNasel treatment) was isolated from the brains of $n=4$ fish per genotype and sex as described in [41]. Then, $500 \mathrm{ng}$ of total RNA $\left(\mathrm{RIN} \mathrm{N}_{\mathrm{e}}>9\right)$ was delivered to the South Australian Genomics Centre (SAGC, Adelaide, Australia) for polyA+ library construction (with unique molecular identifiers (UMIs)) and RNA-sequencing using the Illumina Novaseq S1 2x100 SE platform.

The raw fastq files from SAGC were provided as $100 \mathrm{bp}$ paired end reads as well as an index file containing the UMIs for each read (over two Novaseq lanes which were subsequently merged). The merged raw data was processed using a developed Nextflow [51] RNA-seq workflow (see https://github.com/sagc-bioinformatics/sagc-rnaseq-nf). Briefly, UMIs were added to headers of each read using fastp (v0.20.1). Alignment of the reads to the zebrafish genome (GRCz11, Ensembl release 98) was performed using STAR (v2.5.3a). Then, reads which contained the same UMI (i.e. PCR duplicates) were deduplicated using the dedup function of umi_tools (version 1.0.1). Finally, the gene-level counts matrix was generated using featureCounts from the Subread (version 2.0.1) package. 
216 Statistical analysis of the RNA-seq data was performed using $R$ [52]. Since lowly expressed

217 genes are considered uninformative for differential expression analysis, we omitted genes with less than 0.1 counts per million (CPM) (following the 10/minimum library size in millions rule described in [53]). Library sizes after omitting the lowly expressed genes ranged between 61 and 110 million reads. These were normalised using the trimmed mean of $\mathrm{M}$ values (TMM) method [54]. To test for differential expression of genes due to heterozygosity

222 for the T428del or W233fs mutation, we used a generalised linear model and likelihood ratio tests using edge $R[55,56]$. A design matrix was specified with the wild type genotype as the

224 intercept, and the T428del/+ and W233fs/+ genotypes as the coefficients. We considered a gene to be differentially expressed (DE) due to each psen1 mutant genotype if the FDR

226 adjusted $p$-value was less than 0.05 .

228 We tested for over-representation of gene ontology (GO) terms within the DE gene lists using goseq [57], using the average transcript length per gene to calculate the probability weighting function (PWF). We considered a GO term to be significantly over-represented within the DE gene lists relative to all detectable genes in the RNA-seq experiment if the

232 FDR-adjusted $p$-value generated by goseq was less than 0.05 .

233 We also performed enrichment analysis on the entire list of detectable genes by calculating

234 the harmonic mean $p$-value from the raw $p$-values calculated from fry [58], camera [59] and 235 fgsea $[60,61]$ as described in [41]. To test for changes to gene expression in a broad range of 
biological processes, we used the KEGG [62] gene sets obtained from MSigDB [63] using the msigdbr package [64]. We also used msigdbr to obtain gene sets which contain genes that show changed expression in response to changes in the Notch signalling pathway (NGUYEN_NOTCH1_TARGETS_UP and NGUYEN_NOTCH1_TARGETS_DN,NOTCH_DN.V1_UP, NOTCH_DN.V1_DN and RYAN_MANTLE_CELL_LYMPHOMA_NOTCH_DIRECT_UP). We also

241 tested for evidence of possible iron dyshomeostasis using gene sets containing genes encoding transcripts which contain iron-responsive elements in their untranslated regions

243 (described in [45]).

Isolation of the zebrafish Q96_K97del mutation in zebrafish psen1 and analysis of its effects on zebrafish brain transcriptomes have been described previously $[45,46]$. That dataset is comprised of brain RNA-seq data for fish heterozygous for the Q96_K97del mutation and their wild type siblings, at 6 months old (young adult) and 24 months old (aged), and under normoxia or hypoxia treatment ( $\mathrm{n}=4$ fish per genotype, age and treatment). In the analysis presented here, we performed enrichment analysis using the methods described above on the entire dataset, but presented the results for the pairwise comparison between 6-monthold Q96_K97del/+ fish and wild type fish under normoxia.

253 To obtain a broader comparison on the effects of the Q96_K97del and T428del mutations,

254 we performed adaptive, elastic-net sparse PCA (AES-PCA) [65] as implemented in the 255 pathwayPCA package [66]. For this analysis, we utilised the HALLMARK [67] gene sets from 
calculated only on the gene expression data from samples heterozygous for an EOfAD-like mutation (Q96_K97del or T428del) and their wild type siblings under normoxia at 6 months of age. Then, the categorical effect of genotype was tested for association with the pathway PCs using a permutation-based regression model as described in [66].

262 The paired end fastq files and the output of featureCounts have been deposited in GEO under accession number GSE164466. Code to reproduce this analysis can be found at

267 An unsolved puzzle regarding the dominant EOfAD mutations of human PSEN1 (and PSEN2) is why these are consistently found to permit production of transcripts in which the reading frame is preserved, while heterozygosity for mutations causing frameshifts (or deleting the genes) does not cause EOfAD. To investigate this quandary in an in vivo model, we initially

271 aimed to generate mutations in zebrafish psen 1 which would be exact equivalents of the

272 T440del and P242fs mutations using homology directed repair (HDR). While screening for

273 the desired mutations, we identified the mutations W233fs and T428del, both likely generated by the non-homologous end joining (NHEJ) pathway of DNA repair. T428del is a 3 nucleotide deletion which, nevertheless, produces a protein-level change exactly equivalent to that observed for the human T440del mutation. Hereafter, for simplicity, we refer to the 
277 T428del mutation as "EOfAD-like". W233fs is an indel mutation causing a frameshift in the

278 second codon downstream of the zebrafish psen1 proline codon equivalent to human PSEN1

279 codon P242. This change is still within the short third lumenal loop of the Psen1 protein (see

280 Figure 1). Assuming no effect on splicing, the frameshift mutation results in a premature
A
Hs PSEN1 exon 7 WT
Hs PSEN1 exon 7 P242LfsX11
Dr psen1 exon 6 WT
Dr psen1 exon 6 W233fs

B
HS PSEN1 exon $12 \mathrm{WT}$
Hs PSEN1 exon $12 \mathrm{~T} 440 \mathrm{del}$
Dr psen1 exon $11 \mathrm{WT}$
Dr psen1 exon $11 \mathrm{~T} 428 \mathrm{del}$
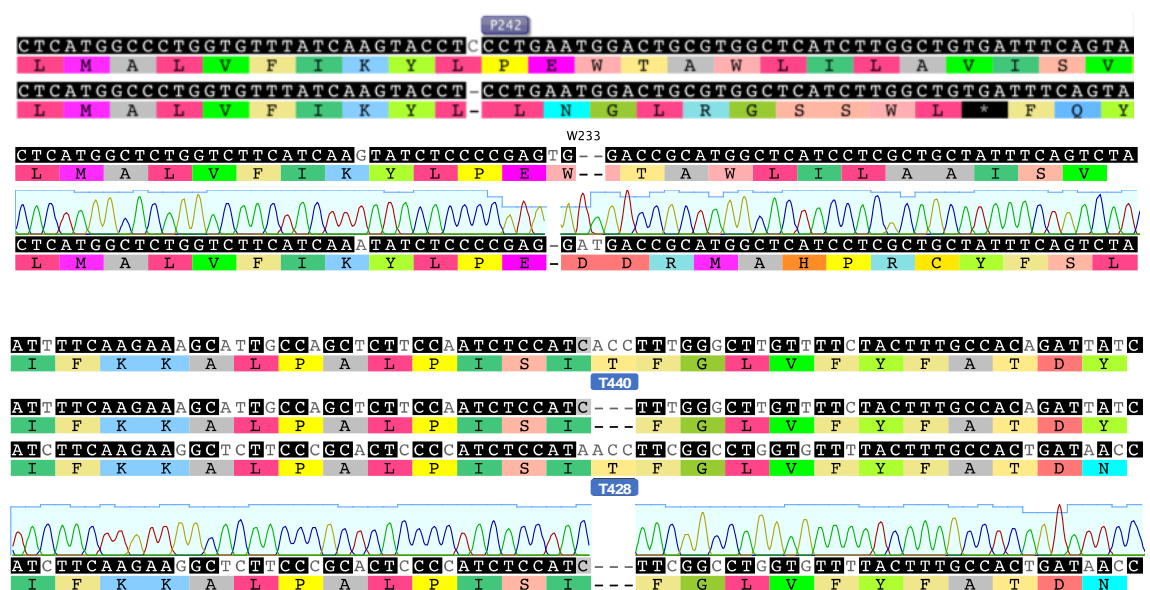
Figure 2: A Alignment of a region of wild type human $(H s)$ PSEN1 exon 7, and the same region containing the human P242fs region of wild type human (Hs) PSEN1 exon 12, and the same region containing the human T440del mutation, and the equivalent zebrafish (Dr) psen1 exon 11 wild type and T428del sequences.

295 To investigate global changes to the brain transcriptome due to heterozygosity for the EOfAD-like or fAl-like mutations in psen1, we performed mRNA-seq on a family of fish as described in Figure 1. The family of sibling fish were raised together in a single tank, thereby reducing sources genetic and environmental variation between individuals and allowing subtle changes to the transcriptome to be detected with minimal confounding effects.

300 To begin our exploration of the similarities and differences between the brain transcriptomes of the mutant and wild type fish, we first performed principal component analysis (PCA) on the gene level, log transformed counts per million (logCPM) of the zebrafish RNA-seq samples. A plot of principal component 1 (PC1) against PC2 did not show distinct clustering of samples by genotype or sex, indicating that these variables do not result in stark changes to the brain transcriptome. This is consistent with our previous observations of EOfAD-like mutations in other genes [39-41]. However, some separation of the EOfAD-like and fAI-like samples is observed across PC2, indicating distinct, but subtle, differences between these transcriptomes. Notably, the majority of the variation in this dataset is not captured until PC6 (Figure 3). 
A

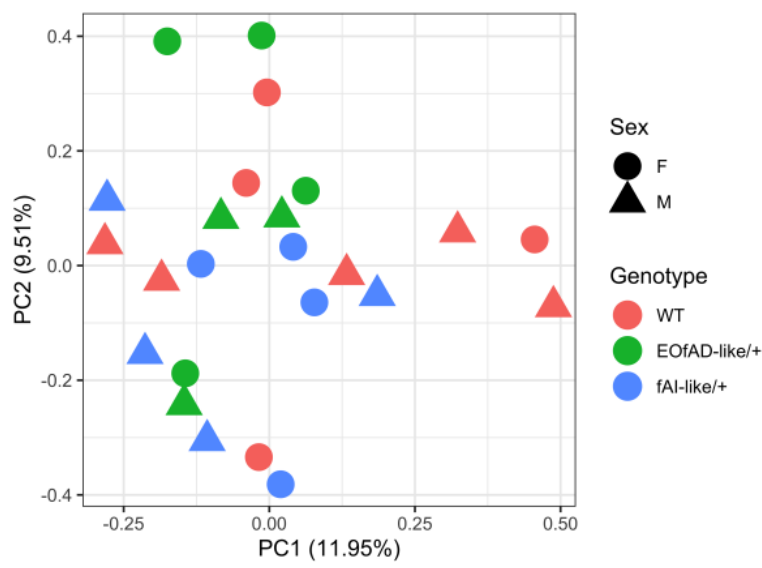

310

311

312

313

314

315

316

317

318

gene expression
B

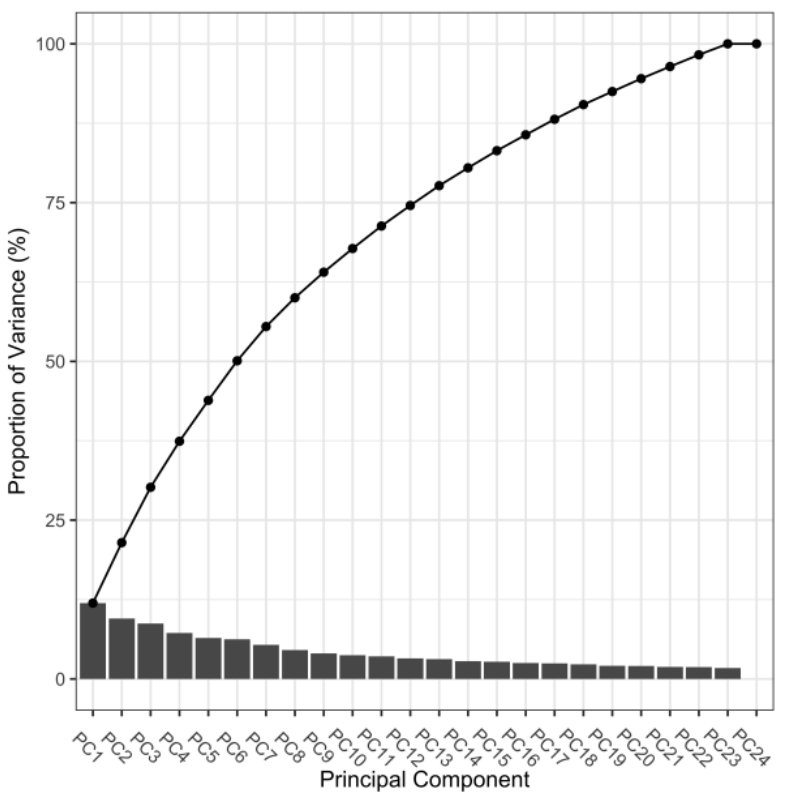

Figure 3: Principal component (PC) analysis of the gene expression values for the RNA-seq experiment. A PC1 plotted against PC2 for each sample. Each point represents a sample and is coloured according to psen1 genotype. Female (F) samples appear as circles and male (M) samples appear as triangles. B Scree plot indicating the variance explained by each principal component. The points joined by lines indicate the cumulative variance explained by each PC. See online version for colour.

Heterozygosity for the EOfAD-like or fAI-like mutations of psen1 causes only subtle effects on

Which genes are dysregulated due to heterozygosity for the EOfAD-like or the fAI-like mutations? To address this question, we performed differential gene expression analysis using a generalised linear model and likelihood ratio tests with edgeR. We observed statistical evidence for 13 genes as significantly differentially expressed (DE) due to heterozygosity for the EOfAD-like mutation, and 5 genes due to the fAl-like mutation (Figure 4, Supplementary Table 1). Notably, psen1 was the most significantly DE gene due to heterozygosity for the fAI-like mutation ( $\log F C=-0.8, F D R=1.33 e-78)$, consistent with the 
observation that frame-shift mutations commonly induce nonsense-mediated mRNA decay

325 when they result in premature stop codons (reviewed in [73]). Total levels of psen1

326 transcripts were unchanged in EOfAD-like/+ brains $(\log F C=-0.0065, F D R=1$, Figure S7 in

327 Supplementary File 2). No DE genes were found to be shared between the comparisons of

328 either form of heterozygous mutant to wild type, or were found to be significantly

329 overrepresented by any gene ontology (GO) terms by goseq (for the top 5 most significantly

330 over-represented GO terms in each comparison, see Tables S1 and S2 in Supplementary File

331 2). This is not unexpected due to the relatively low number of significantly DE genes

332 detected. 
bioRxiv preprint doi: https://doi.org/10.1101/2021.01.26.428321; this version posted February 9, 2021. The copyright holder for this preprint (which was not certified by peer review) is the author/funder, who has granted bioRxiv a license to display the preprint in perpetuity. It is made available under aCC-BY-NC 4.0 International license.
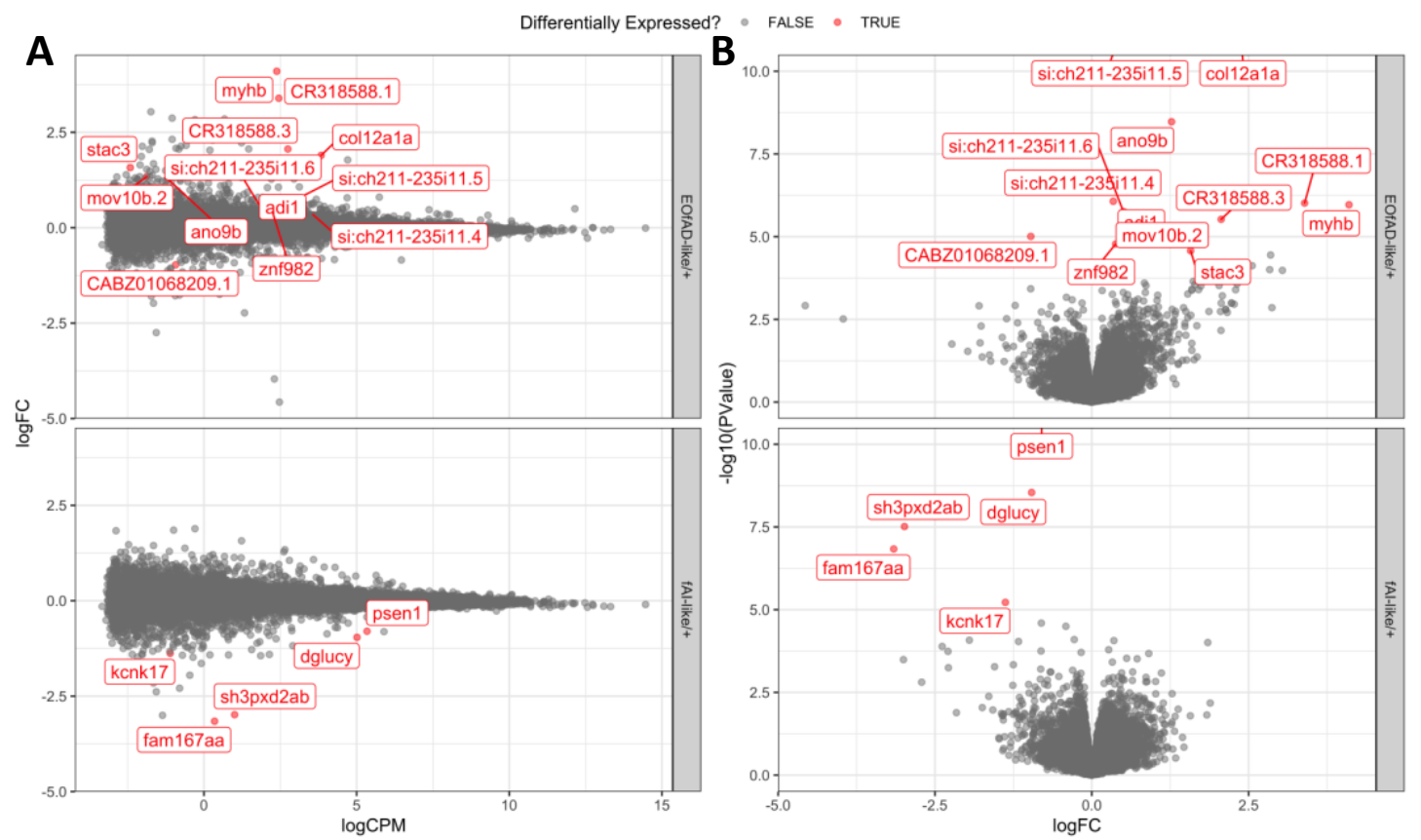

C

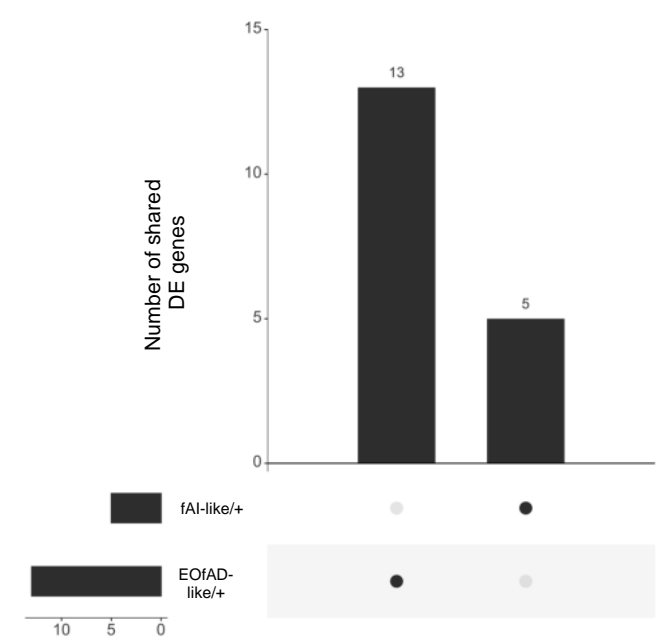

Number of DE genes

334 Figure 4: Differential expression analysis. A Mean-difference (MD) plots and B volcano plots of changes to gene expression in

335 EOfAD-like/+ and fAI-like/+ mutant zebrafish brains. Note that the limits of the $y$-axis in $\mathbf{B}$ are restrained to between 0 and 10 for

336 visualisation purposes. C Upset plot indicating the low number of genes which are significantly differentially expressed (DE) in either comparison. See online version for colour. 
bioRxiv preprint doi: https://doi.org/10.1101/2021.01.26.428321; this version posted February $9,2021$. The copyright holder for this preprint (which was not certified by peer review) is the author/funder, who has granted bioRxiv a license to display the preprint in perpetuity. It is made available under aCC-BY-NC 4.0 International license.

340 Since very few DE genes were detected in each comparison of heterozygous psen 1 mutant fish to their wild type siblings, we performed enrichment analysis on all detectable genes in the RNA-seq experiment. Our method, inspired by the EGSEA framework [74], involves calculation of the harmonic mean $p$-value [75] from the raw $p$-values of three different rankbased gene set testing methods: fry [58], camera [59] and GSEA [60, 61]. Unlike EGSEA, we use the harmonic mean $p$-value to combine the raw $p$-values, as the harmonic mean $p$-value has been specifically shown to be robust for combining dependent p-values [75]. We performed enrichment testing using the KEGG gene sets (describing 186 biological pathways and processes) to obtain information on changes to activities for these pathways. We also tested for evidence of iron dyshomeostasis using our recently defined sets of genes containing iron-responsive elements (IREs) in the untranslated regions of their mRNAs [45].

We observed statistical evidence for 7 KEGG gene sets as significantly altered by heterozygosity for the EOfAD-like mutation and 11 KEGG gene sets as significantly altered by heterozygosity for the fAl-like mutation (Figure 5, full results of the raw $p$-values from each algorithm as well as the harmonic mean p-value can be found in Supplementary Table 2). the KEGG gene sets for cytokine receptor interactions, Jak/Stat signalling, and encoding the components of the ribosomal subunits. Inspection of the leading edge genes (which can be interpreted as the core genes driving the enrichment of a gene set) showed that similar genes were driving the enrichment of the gene sets for cytokine receptor interactions and 
gene set in both heterozygous mutants. However, the magnitude of the logFC was greater in the fAl-like/+ samples, suggesting a stronger effect (Figure S4-S6 in Supplementary File 2).

363 Gene sets which were only altered significantly by heterozygosity for the EOfAD-like

364 mutation were involved in energy metabolism (KEGG_PARKINSONS_DISEASE, KEGG_OXIDATIVE_PHOSPHORYLATION, and KEGG_CITRATE_CYCLE_TCA_CYCLE). Notably, the KEGG gene sets for Parkinson's disease, Huntington's disease, and for oxidative

367 phosphorylation, share 55 leading-edge genes, implying that their enrichment is driven by, essentially, the same gene expression signal (Figure 5). Conversely, the 10 KEGG gene sets found to be altered significantly by heterozygosity for the fAl-like mutation appear to be driven mostly by distinct gene expression signals. No IRE gene sets were observed

371 statistically to be altered in the brains of either mutant, suggesting that iron homeostasis is unaffected (at least at 6 months of age). The changes to expression of genes within the KEGG gene sets are likely not due to broad changes in cell-type proportions in the zebrafish brain samples, since the expression of marker genes of neurons, astrocytes, oligodendrocytes and

375 microglia was similar in all samples (Figure S13 in Supplementary File 2). 
bioRxiv preprint doi: https://doi.org/10.1101/2021.01.26.428321; this version posted February 9, 2021. The copyright holder for this preprint (which was not certified by peer review) is the author/funder, who has granted bioRxiv a license to display the preprint in perpetuity. It is made available under aCC-BY-NC 4.0 International license.

A

Both

$-\log 10($ harmonic_p) $\quad 5 \quad 10 \quad 15$

EOfAD-like/+ only

fAl-like/+ only

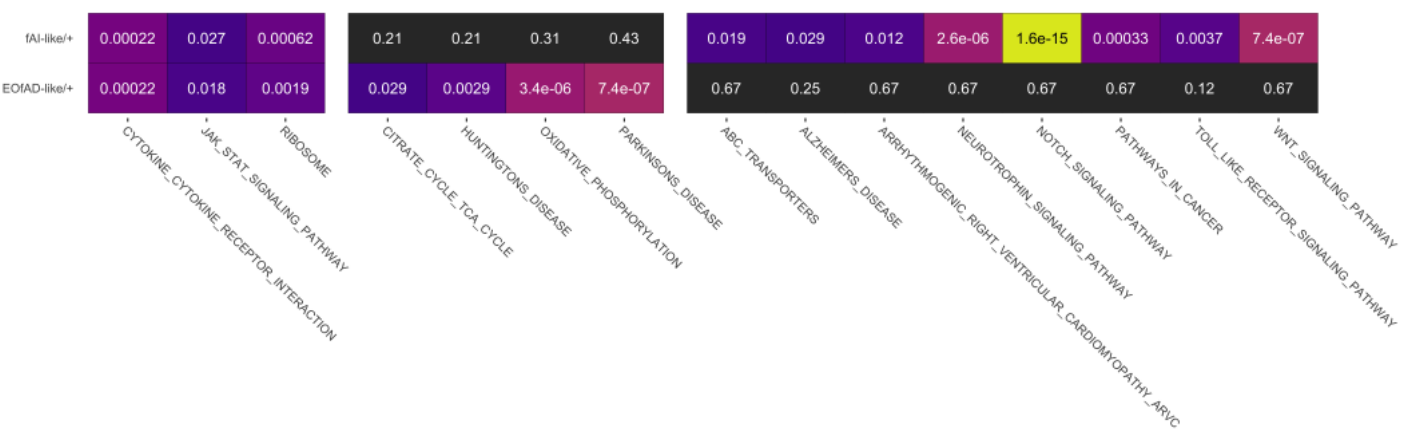

B

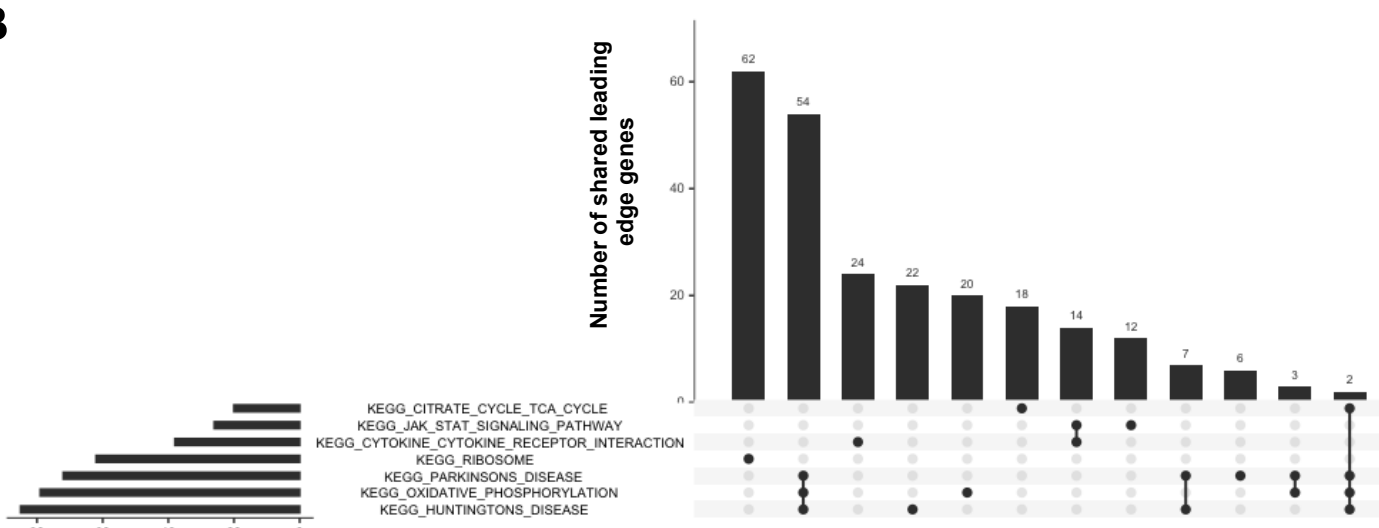

Number of genes in leading edge

C

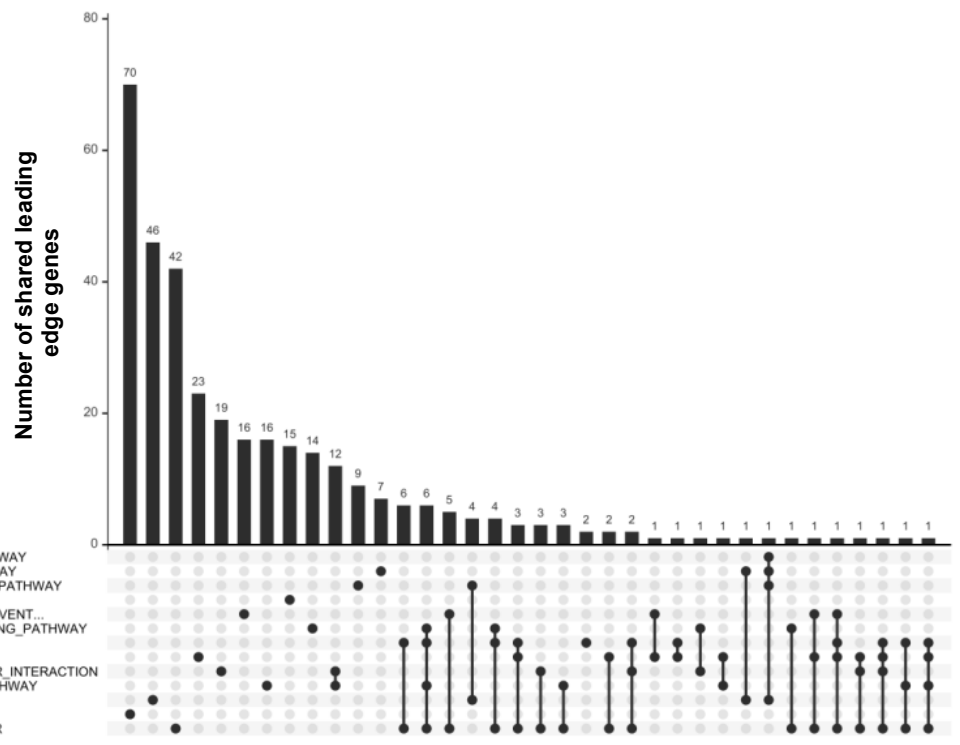

Number of genes in leading edge 
Figure 5: A KEGG gene sets with FDR-adjusted harmonic mean p-values of $<0.05$ in psen1 EOfAD-like/+ and fAl-like/+ mutant

383 Notch signalling plays a critical role in many cell differentiation events and is dependent on of genes involved in the KEGG gene set for the Notch signalling pathway was observed to be highly significantly altered in the brains of fAl-like/+ mutants, but not of EOfAD/+ mutants, implying that $\gamma$-secretase activity might only be affected significantly by the frameshift, fAllike mutation (Figure 5). However, inspection of the logFC of genes in the expression in both mutants (Figure 6). Upregulation of the genes encoding the Notch and observe downregulation of the downstream transcriptional targets of the Notch intracellular 
400

401

402

403

404

405

406

407

408

409

410

411

412

413

414

415

416

417

418

419

420

421

422

423

Since the KEGG gene set for Notch signalling only contains two genes that are direct

transcriptional targets of the NICD, we investigated further whether Notch signalling is

perturbed in both mutants by analysis of gene sets from MSigDB containing information on genes responsive to Notch signalling in different cell lines: NGUYEN_NOTCH1_TARGETS_UP;

NGUYEN_NOTCH1_TARGETS_DN; NOTCH_DN.V1_UP; NOTCH_DN.V1_DN; and

RYAN_MANTLE_CELL_LYMPHOMA_NOTCH_DIRECT_UP.The

NGUYEN_NOTCH1_TARGETS_UP and_DOWN gene sets consist of genes which have been

observed as up- or downregulated respectively in response to a constitutively active Notch

receptor in keratinocytes [80]. The NOTCH_DN.V1_UP and_DN gene sets contain genes

which are up- and down-regulated respectively in response to treatment with the $\gamma$ -

secretase inhibitor DAPT in a T-cell acute lymphoblastic leukemia (T-ALL) cell line [81]. The

RYAN_MANTLE_CELL_LYMPHOMA_NOTCH_DIRECT_UP gene set contains genes showing

both increased expression upon rapid activation of Notch signalling by washout of the $\gamma$ -

secretase inhibitor compound E, and evidence for a NICD binding site in the promotor by

ChIP-seq, in mantle cell lymphoma cell lines [82]. (Note that there is no equivalent

"RYAN_MANTLE_CELL_LYMPHOMA" gene set representing genes downregulated in

response to Notch signalling.) Of these 5 gene sets, statistical support was found only for

changes to the expression of genes in the

RYAN_MANTLE_CELL_LYMPHOMA_NOTCH_DIRECT_UP gene set, and this was found for

both the EOfAD-like $(p=0.006)$ and the fAl-like $(p=0.008)$ mutants. The leading edge genes

were mostly observed to be upregulated, which supports increases in Notch signalling

(implying increased $\gamma$-secretase activity). Transcriptional adaptation (previously known as

"genetic compensation") might contribute to the apparent increase in Notch signalling in the frameshift, fAl-like/+ mutant brains via upregulated expression of the psen1-homologous 
gene, psen2 [83, 84]. Although no statistically significant differences in expression were

425 observed for psen2 in the differential expression test using edgeR (see Supplementary Table

426 1), a trend towards upregulation in the fAl-like/+ mutants was observed following a simple

427 Student's t-test ( $p=0.074$, Figure 6D). El-Brolosy et al. [83] showed that the wild type allele of

428 a mutated gene can also be upregulated by transcriptional adaptation (where the mutation

429 causes nonsense-medicated decay, NMD, of mutant transcripts). Inspection of the number

430 of reads aligning to the W233 mutation site across samples indicates that the expression of

431 the wild type psen 1 allele in fAl-like/+ brains appears to be greater than $50 \%$ of the

432 expression of the wild type psen 1 allele in wild type brains $(p=0.006)$, providing further

433 evidence for transcriptional adaptation due to the fAl-like mutation (Figure S8 in

\section{Supplementary File 2).}

435 Together, these results suggest that Notch signalling and, by implication, $\gamma$-secretase activity,

436 may be enhanced in psen1 mutant brains. However, future biochemical assays should be

437 performed to confirm this prediction. 

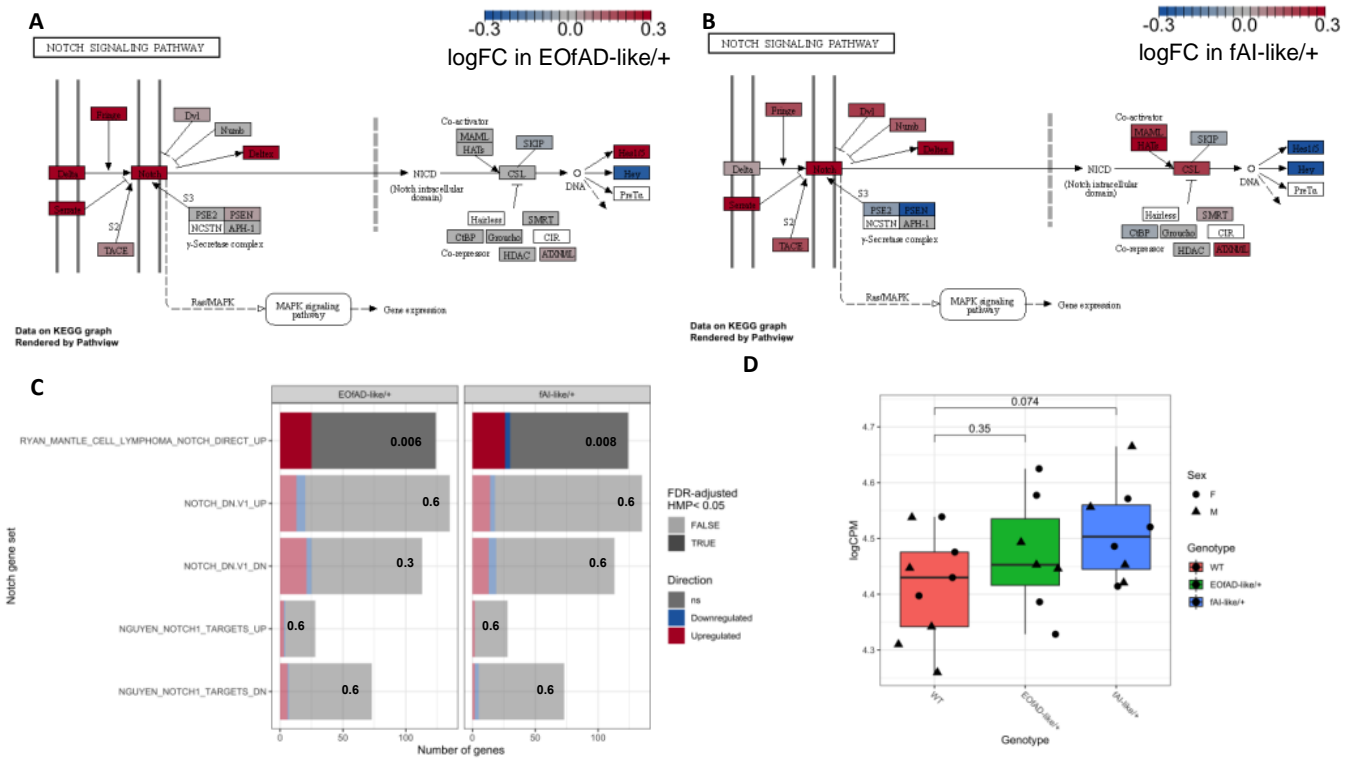

E

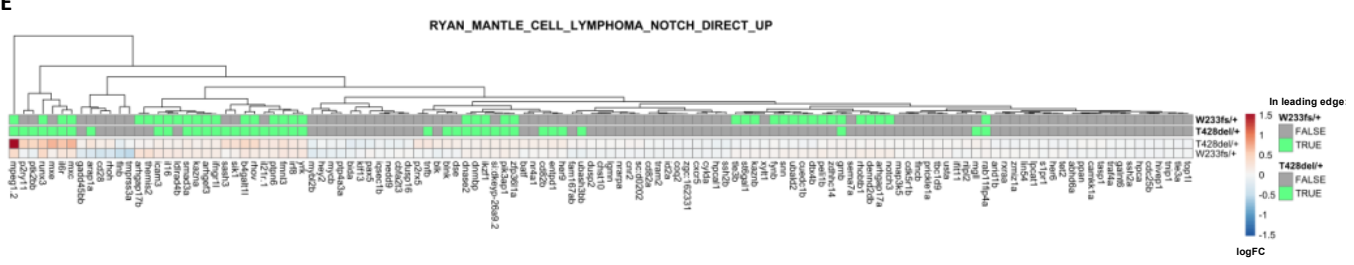

Figure 6: A Pathview [85] visualisation of the changes to gene expression in the KEGG_NOTCH_SIGNALING_PATHWAY

440 gene set in EOfAD-like/+ mutants and B fAl-like/+ mutants. C The proportion of genes with increased expression (red, $z>\sqrt{ } 2$ )

441 and decreased expression (blue, $z<\sqrt{ } 2$ ) in MSigDB gene sets for Notch signalling in EOfAD-like/+ and fAl-like/+ mutant brains.

442 Gene sets which contained a FDR-adjusted harmonic mean p-value (HMP) $<0.05$ appear less transparent. The FDR adjust $p$ -

443 values are also listed on the bars. D The expression of psen2 is trending towards upregulation, particularly in fAl-like/+ mutants.

444 Here, p-values were determined by Student's unpaired t-tests. E Heatmap indicating the logFC values for genes in the

445 RYAN_MANTLE_CELL_LYMPHOMA_NOTCH_DIRECT_UP gene set. Genes are clustered based on their Euclidean distance,

446 and are labelled with green if they appear in the leading edge of the fgsea algorithm for each comparison of a psen 1

447 heterozygous mutant with wild type. See online version for colour.

448 The EOfAD-like mutation T428del has a milder phenotype than the previously studied

450 The T428del mutation of psen1 is the first identified zebrafish mutation exactly equivalent,

451 (at the protein sequence level), to a characterised human EOfAD mutation. Therefore, we 
sought to assess the consistency of its effects with those of a previously studied EOfAD-like mutation, Q96_K97del, and to identify cellular processes affected in common by the two mutations. The Q96_K97del mutation deletes two codons in the sequence encoding the first lumenal loop of the Psen1 protein (see Figure 1). Comparison of transcriptomes from the 6month-old brains of Q96_K97del/+ and wild type siblings previously predicted changes to expression of genes involved in energy metabolism, iron homeostasis and lysosomal acidification $[45,46]$. To compare which cellular processes are affected by heterozygosity for the Q96_K97del mutation or the T428del mutation, we first performed enrichment analysis on the RNA-seq data previously generated by our analysis of zebrafish heterozygous for the Q96_K97del mutation relative to their wild type siblings. Here, we observed that heterozygosity for the Q96_K97del mutation results in significant alterations in 7 KEGG gene sets (at 6 months of age during normoxia, Figure 7A). We also found statistical evidence for altered expression of genes possessing IREs in their 3' UTRs (see IRE3_ALL in Figure 7A), consistent with our previous finding using a different method of enrichment analysis [45]. in energy metabolism and protein translation (Figure 7A). The expression of genes involved in protein degradation, and of genes containing IREs in the 3' UTRs of their transcripts, appeared significantly altered only by the Q96_K97del mutation (Figure 7A).

470 We also compared the effects of the two EOfAD-like mutations using adaptive, elastic-net 471 sparse PCA (AES-PCA) as implemented in the pathwayPCA package [66]. AES-PCA allows

472 reduction of data dimensionality and for the overall activity of predefined gene sets to be 473 observed in a sample-specific manner [65]. To obtain a global view of the changes to gene expression between the two psen1 EOfAD-like mutations over the two datasets, we utilised 
the HALLMARK gene sets that encompass 50 distinct biological processes (rather than the 186 KEGG gene sets that share many genes).

477 The latent variables estimated by AES-PCA for the HALLMARK gene sets (i.e. the first

478 principal components) in each dataset did not show any significant association with psen1

479 genotype, suggesting that changes to gene expression (measured over entire brains) are too

480 subtle to be detected as statistically significant using this method. However, clustering of the

481 calculated PC1 values by AES-PCA for each HALLMARK gene set in each sample and dataset

482 revealed that samples in the Q96_K97del dataset clustered mostly according to genotype

483 (one wild type sample did not follow the trend), supporting that heterozygosity for the

484 Q96_K97del mutation does result in marked effects on gene expression for the HALLMARK

485 gene sets. Conversely, clustering of PC1 values in the T428del dataset resulted in two distinct

486 clusters of samples. However, samples did not group by genotype over the two clusters to

487 the same extent as seen for the Q96_K97del dataset. Intriguingly, the Q96_K97del dataset

488 had less sample numbers per genotype $(n=4)$, and did not have as great sequencing depth

489 as the current RNA-seq experiment. Therefore, this supports that heterozygosity for the

490 Q96_K97del mutation has more consistent (more severe) effects on young adult brain 
bioRxiv preprint doi: https://doi.org/10.1101/2021.01.26.428321; this version posted February 9, 2021. The copyright holder for this preprint (which was not certified by peer review) is the author/funder, who has granted bioRxiv a license to display the preprint in perpetuity. It is made available under aCC-BY-NC 4.0 International license.

A
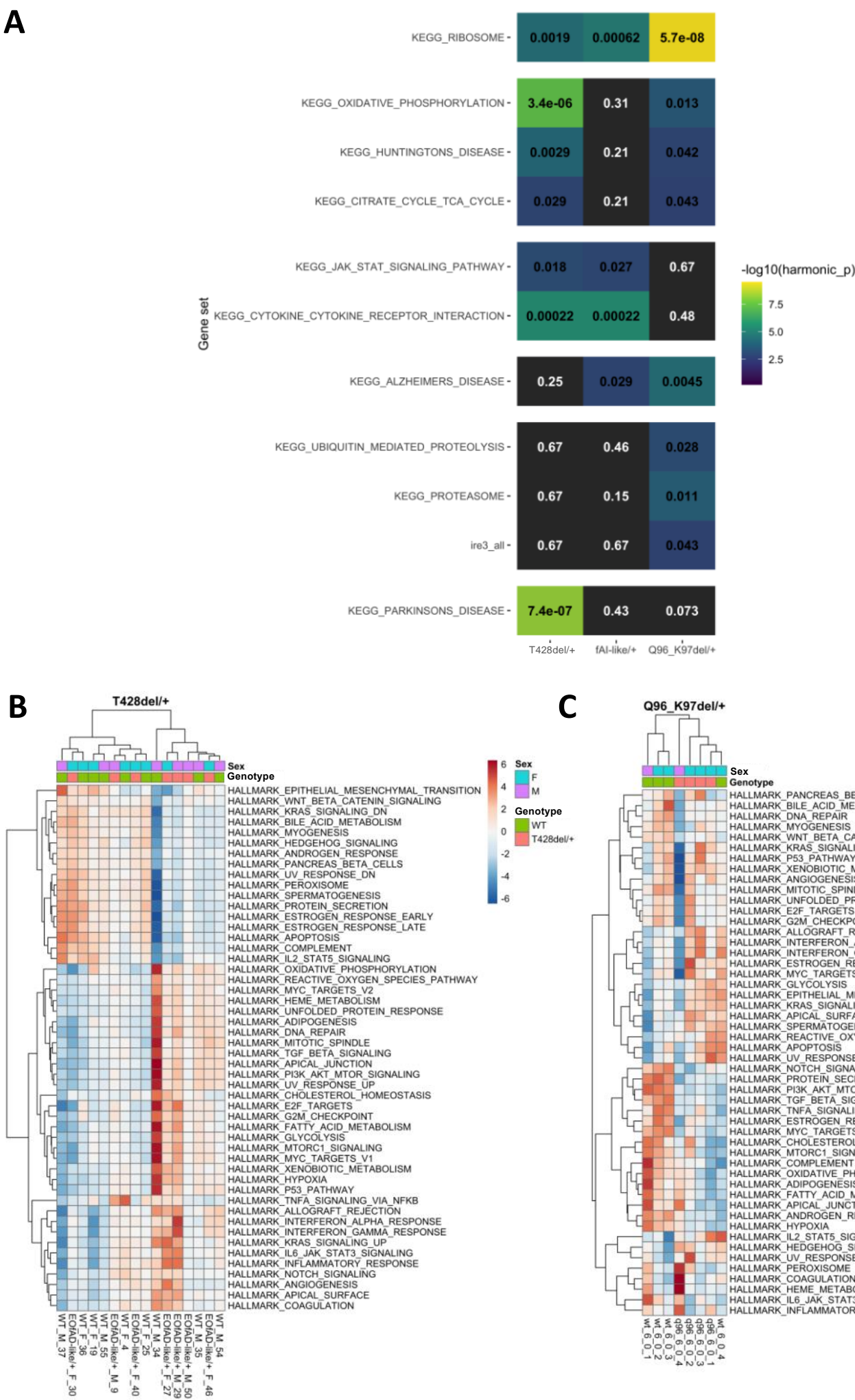

C Q966 K97del/+

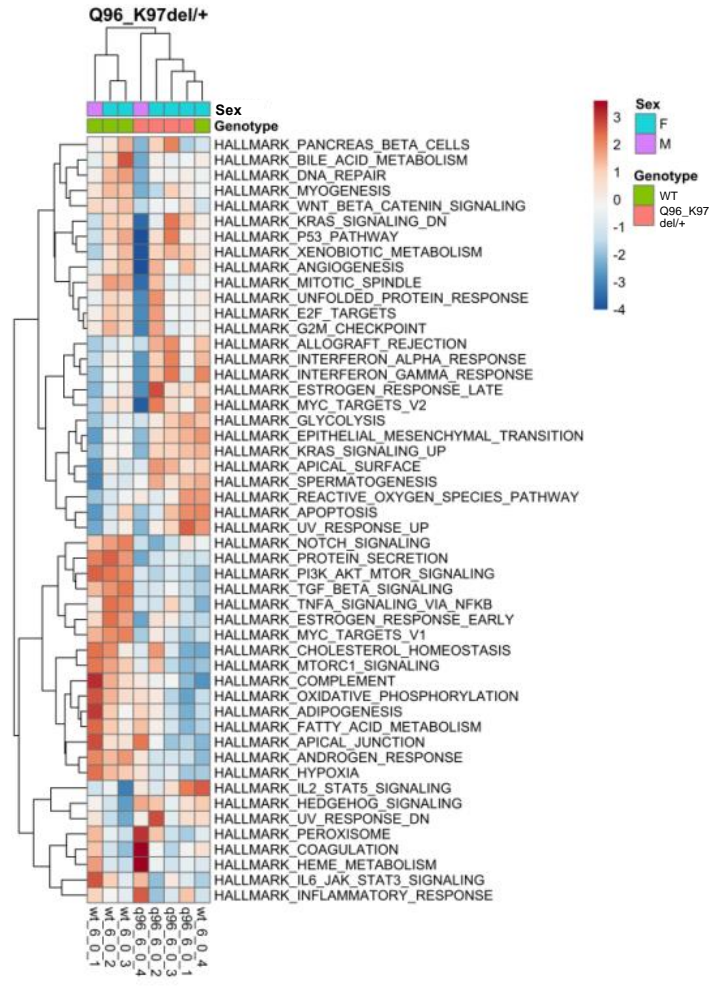


bioRxiv preprint doi: https://doi.org/10.1101/2021.01.26.428321; this version posted February 9, 2021. The copyright holder for this preprint (which was not certified by peer review) is the author/funder, who has granted bioRxiv a license to display the preprint in perpetuity. It is made available under aCC-BY-NC 4.0 International license.

493 Figure 7: A Comparison of KEGG and IRE gene sets significantly altered by the EOfAD-like mutations T428del and

494 Q96_K97del in 6-month-old zebrafish brains. Each cell is coloured according to statistical significance, and the FDR-adjusted

495 harmonic mean $p$-value is shown. Gene sets not significantly altered (FDR adjusted harmonic mean p-value > 0.05) in a

496 comparison between a psen 1 mutant zebrafish with their respective wild type siblings appear grey. B Principal component 1

497 (PC1) values for the HALLMARK gene sets as calculated by AES-PCA, clustered based on their Euclidean distance in

498 T428del/+ samples relative to their wild type siblings. C PC1 values for the HALLMARK gene sets as calculated by AES-PCA

499 clustered based on their Euclidean distance in Q96_K97del/+ samples relative to their wild type siblings at 6 months of age

500 under normal oxygen conditions. See online version for colour. 
In this study, we exploited transcriptome analysis of whole brains of young adult zebrafish

504 siblings, to detect differences in molecular state between the brains of fish heterozygous for an EOfAD-like mutation or an fAI-like mutation of psen1 compared to wild type in vivo. The

506 subtlety of the effects observed is consistent with that EOfAD is, despite its designation as

507 "early-onset", a disease affecting people overwhelmingly at ages older than 30 years [86].

508 The person reported to carry the T440del mutation of PSEN1 showed cognitive decline at 41

509 years [47]. (Overall, EOfAD mutations in PSEN1 show a median survival to onset of 45 years

510 [86]). In contrast, at 6 months of age, zebrafish are only recently sexually mature.

511 Nevertheless, since AD is thought to take decades to develop [32], it is these subtle, early

512 changes that we must target therapeutically if we wish to arrest the pathological processes

513 driving the progression to AD. As seen in all our previous analyses of EOfAD-like mutations

$514[39-41,43,45]$, changes in expression of genes involved in oxidative phosphorylation were

515 identified as significant. However, this was not the case for the fAl-like, frameshift mutation.

516 Therefore, oxidative phosphorylation changes appear to be an early signature cellular stress

517 of EOfAD. Changes to mitochondrial function have been observed in heterozygous PSEN1

518 mutant astrocytes [87], homozygous PSEN1 mutant neurons [88], and in neurons

519 differentiated from human induced pluripotent stem cells (hIPSCs) from sporadic AD

520 patients [89], supporting our findings. However, such changes are not always observed [90],

521 possibly due to issues of experimental reproducibility between laboratories when working 522 with hIPSCs [91]. 
The EOfAD-like mutation also caused very statistically significant changes in the

535 Both the EOfAD-like and fAl-like mutations caused very statistically significant changes in the

537 former gene set reflects that both mutations appear to affect inflammation that is a

539 phosphorylation, we have also observed effects on ribosomal protein genes sets for every

540 EOfAD-like mutation we have studied [39-41, 43]. This may be due protein synthesis

541 consuming a large proportion of cells' energy budgets [95] and requiring amino acid

542 precursors that can be sourced from lysosomes. Recently, Bordi et al [96] noted that mTOR

543 is highly activated in fibroblasts from people with Down syndrome (DS, trisomy 21). DS

544 individuals commonly develop EOfAD due to overexpression of the A $\beta P P$ gene (that is 
resident on human chromosome 21). The consequent increased expression of A $\beta P P^{\prime}$ s $\beta$ -

$546 \mathrm{CTF} / \mathrm{C99}$ fragment (generated by $\beta$-secretase cleavage of AßPP without $\gamma$-secretase cleavage)

547 affects endolysosomal pathway acidification [97] in a similar manner to EOfAD mutations of

548 PSEN1 [98]. The mTOR protein is localised at lysosomes in the mTORC1 and mTORC2 protein

549 complexes (reviewed in $[99,100])$ and monitors the energy and nutrient status of cells

550 (reviewed in [101]). It is important for regulating ribosomal activity, partly by regulating

551 transcription of ribosome components (reviewed in $[102,103])$. Therefore, one explanation

552 for the consistent enrichment for transcripts of the KEGG_RIBOSOME gene set we see in

553 EOfAD mutant brains may be mTOR activation due to effects on lysosomal acidification

554 and/or the energy status of cells. We did not observe any significant changes to the

555 expression of genes involved in the mTOR signalling pathway in the analyses described in

556 this paper (the FDR-adjusted harmonic mean p-value for the

557 KEGG_MTOR_SIGNALING_PATHWAY was 0.7 for each comparison of the psen 1 mutant fish

558 to their wild type siblings, see Supplementary Table 2). However, these changes could be

559 undetectably subtle in young adult brains and/or occurring at the protein level and therefore

560 not observable in bulk RNA-seq data. (Statistically significant enrichment for genes in the

561 HALLMARK_PI3K_AKT_MTOR_SIGNALING gene set was seen previously for the normoxic, 6-

562 month-old brains of fish heterozygous for the more severe EOfAD-like mutation Q96_K97del

563 when compared to wild type siblings [45].)

564 While the brain transcriptome alterations caused by the EOfAD-like and fAI-like mutations

565 are subtle (as illustrated by the lack of tight clustering of samples in the principal component

566 analysis in Figure 3, and the low number of significantly differentially expressed genes), we

567 are reassured in their overall veracity by their similarity to the results of a parallel analysis of 
sibling brain transcriptomes from 6-month-old zebrafish heterozygous for either a frameshift or a frame-preserving mutation in the zebrafish psen2 gene relative to wild type [40]. In that similarly structured (but less statistically powered) experiment, only the frameshift mutation significantly affected the KEGG_NOTCH_SIGNALLING gene set while only the framepreserving, EOfAD-like mutation significantly affected the KEGG_OXIDATIVE_PHOSPHORYLATION gene set. Both psen2 genotypes affected the

574 KEGG_RIBOSOME gene set, but in overall opposite directions (the frameshift mutation 575 largely upregulated these genes while the frame-preserving mutation did the opposite).

576 Transcriptome analysis can reveal a great deal of data on differences in gene transcript levels

577 between different genotypes or treatments. However, interpreting changes in cellular state 578 from this information is not straight forward. Are any changes seen direct molecular effects 579 of a mutation/treatment (e.g. the direct, downstream effects of a change in $\gamma$-secretase activity) or homeostatic responses as cells/tissues adjust their internal states to promote survival? For example, in the KEGG_NOTCH_SIGNALING_PATHWAY gene set shown in Figure 6B, more pathway components are upregulated than are downregulated. However, the direct transcriptional targets of Notch signalling (her4.2 and heyl) are downregulated, as might be expected from reduced expression of wild type, catalytically-competent Psen1 protein. The upregulation of other components of the pathway may represent homeostatic responses attempting to restore normal levels of Notch signalling. 
analysed additional sets of genes previously identified (in various systems) as direct

591 transcriptional targets of $\gamma$-secretase-dependent signalling. One of these sets, encompassing

593 binding of the Notch intracellular domain to chromatin, revealed apparent upregulation of

594 Notch signalling in both the EOfAD-like and fAl-like heterozygous mutant brains relative to wild type siblings. In both EOfAD-like/+ and fAI-like/+ mutant brains, the most highly ranked genes in terms of differential expression tended to be upregulated (although some highly examining the activities of the mutant proteins in isolation from wild type protein). Zhou et

608 fragment) due to an EOfAD mutation of PSEN1 (S365A, this replicated Sun et al.'s finding for 609 this mutation).

610 It is important to note that mutations of PSEN1 need not cause similar effects on Notch and 611 A $\beta$ PP cleavage $[104,107,108]$. The transmembrane domains of the Notch receptor and the 612 APP's C99 fragment have different conformations [109]. Therefore, changes in the 
conformation of PSEN1 within $\gamma$-secretase due to a mutation may differentially affect Notch

614 and C99 cleavage. Indeed, in our previously mentioned study of forced expression of the human PSEN1 ${ }^{\text {P242Lfs }}$ allele in zebrafish embryos, increased apparent Notch signalling was observed without change in A $\beta$ PP processing [104]. Conversely, Zhang et al. [108] showed that transgenic expression of an EOfAD mutation S169del in PSEN1 under the control of the Thy1 brain specific promotor altered the processing of ABPP in vivo without affecting Notch signalling. Notably, both of these studies did not use the PSEN1 gene's own promoter to express mutant forms of this gene, and so the effects seen may be distorted by gene/protein over-expression. have not been characterised to the same extent as those of NICD (reviewed in [110]). This constrains transcriptome analysis for detection of differential effects on $\gamma$-secretase cleavage of A PPP caused by the EOfAD-like and fAl-like mutations. Future work should include further investigation of how these mutations effect $\gamma$-secretase cleavage of AßPP in vivo. mutation of presenilin 1 in an in vivo model. Both forms of mutation cause apparent changes in inflammation, downregulate expression of genes encoding the components of the ribosome subunits, and potentially affect $\gamma$-secretase activity as supported by altered expression of Notch signalling pathway transcriptional target genes. We see that changes to mitochondrial function are a specific, common characteristic of EOfAD-like mutations while the fAl-like mutation specifically affects important signal transduction pathways. These 
differential effects on brain transcriptomes give insight into how reading-frame preserving mutations in PSEN1 cause EOfAD while frameshift mutations do not.

639 The authors would like to thank Dr. Nhi Hin for providing the Q96_K97del gene expression

640 values and the zebrafish IRE gene sets. We also would like to thank Dr. Jimmy Breen for his

641 assistance with using the Nextflow pipeline. The authors thank Dr Giuseppe Verdile for

642 critical reading of the manuscript.

643 This work was supported with supercomputing resources provided by the Phoenix HPC

644 service at the University of Adelaide and by grants GNT1061006 and GNT1126422 from the

645 National Health and Medical Research Council of Australia (NHMRC). KB was supported by

646 an Australian Government Research Training Program Scholarship and by funds from the

647 Carthew Family Charity Trust. YD was supported by an Adelaide Graduate Research

648 Scholarship from the University of Adelaide. MN was supported by funds from the grants

649 listed above. ML is an academic employee of the University of Adelaide. 
[1] Janssen JC, Beck JA, Campbell TA, Dickinson A, Fox NC, Harvey RJ, Houlden H, Rossor MN, Collinge J (2003) Early onset familial Alzheimer's disease: Mutation frequency in 31 families. Neurology 60, 235-239.

[2] Żekanowski C, Styczyńska M, Pepłońska B, Gabryelewicz T, Religa D, Ilkowski J, Kijanowska-Haładyna B, Kotapka-Minc S, Mikkelsen S, Pfeffer A, Barczak A, Łuczywek E, Wasiak B, Chodakowska-Żebrowska M, Gustaw K, Łączkowski J, Sobów T, Kuźnicki J, Barcikowska M (2003) Mutations in presenilin 1, presenilin 2 and amyloid precursor protein genes in patients with early-onset Alzheimer's disease in Poland. Experimental Neurology 184, 991-996.

[3] Cruts $M$, van Duijn CM, Backhovens $H$, Van den Broeck $M$, Wehnert A, Serneels S, Sherrington R, Hutton M, Hardy J, St George-Hyslop PH (1998) Estimation of the genetic contribution of presenilin-1 and-2 mutations in a population-based study of

[4] Kamimura K, Tanahashi H, Yamanaka H, Takahashi K, Asada T, Tabira T (1998) Familial Alzheimer's disease genes in Japanese. Journal of the neurological sciences 160, 7681.

[5] Area-Gomez E, de Groof AJ, Boldogh I, Bird TD, Gibson GE, Koehler CM, Yu WH, Duff KE, Yaffe MP, Pon LA, Schon EA (2009) Presenilins are enriched in endoplasmic reticulum membranes associated with mitochondria. American Journal of Pathology 175, 1810-1816. Biol Chem 280, 35352-35360.

Fukumori A, Fluhrer R, Steiner H, Haass C (2010) Three-amino acid spacing of presenilin endoproteolysis suggests a general stepwise cleavage of gamma-secretase- 
680

681

682

683

684

685

686

687

688

689

690

691

692

693

694

695

696

697

698

699

700

701

702

703

704

705

706

707

708

709

710

[9] Sun L, Zhao L, Yang G, Yan C, Zhou R, Zhou X, Xie T, Zhao Y, Wu S, Li X, Shi Y (2015) Structural basis of human $\gamma$-secretase assembly. Proceedings of the National Academy of Sciences 112, 6003.

[10] Wolfe MS (2020) Unraveling the complexity of $y$-secretase. Semin Cell Dev Biol 105, 3-11.

[11] Dermaut B, Kumar-Singh S, Engelborghs S, Theuns J, Rademakers R, Saerens J, Pickut BA, Peeters K, van den Broeck M, Vennekens K, Claes S, Cruts M, Cras P, Martin JJ, Van Broeckhoven C, De Deyn PP (2004) A novel presenilin 1 mutation associated with Pick's disease but not beta-amyloid plaques. Ann Neurol 55, 617-626.

[12] Li D, Parks SB, Kushner JD, Nauman D, Burgess D, Ludwigsen S, Partain J, Nixon RR, Allen CN, Irwin RP, Jakobs PM, Litt M, Hershberger RE (2006) Mutations of presenilin genes in dilated cardiomyopathy and heart failure. Am J Hum Genet 79, 1030-1039.

[13] Wang B, Yang W, Wen W, Sun J, Su B, Liu B, Ma D, Lv D, Wen Y, Qu T, Chen M, Sun M, Shen Y, Zhang X (2010) -Secretase Gene Mutations in Familial Acne Inversa. 330, 1065-1065.

[14] Jiang H, Jayadev S, Lardelli M, Newman M (2018) A Review of the Familial Alzheimer's Disease Locus PRESENILIN 2 and Its Relationship to PRESENILIN 1. Journal of Alzheimer's Disease 66, 1323-1339.

[15] Sun L, Zhou R, Yang G, Shi Y (2017) Analysis of 138 pathogenic mutations in presenilin- 1 on the in vitro production of $A \beta 42$ and $A \beta 40$ peptides by $\gamma$-secretase. Proceedings of the National Academy of Sciences 114, E476-E485.

[16] Szaruga M, Veugelen S, Benurwar M, Lismont S, Sepulveda-Falla D, Lleo A, Ryan NS, Lashley T, Fox NC, Murayama S, Gijsen H, De Strooper B, Chávez-Gutiérrez L (2015) Qualitative changes in human $\gamma$-secretase underlie familial Alzheimer's disease. J Exp Med 212, 2003-2013.

[17] De Strooper B (2007) Loss-of-function presenilin mutations in Alzheimer disease. Talking Point on the role of presenilin mutations in Alzheimer disease. EMBO Rep 8, 141-146.

[18] Jayne T, Newman M, Verdile G, Sutherland G, Munch G, Musgrave I, Moussavi Nik SH, Lardelli M (2016) Evidence for and Against a Pathogenic Role of Reduced gammaSecretase Activity in Familial Alzheimer's Disease. Journal of Alzheimer's Disease. 
[19] Wong TH, Seelaar H, Melhem S, Rozemuller AJM, van Swieten JC (2020) Genetic screening in early-onset Alzheimer's disease identified three novel presenilin mutations. Neurobiology of aging 86, 201.e209-201.e214.

[20] Lee JH, McBrayer MK, Wolfe DM, Haslett LJ, Kumar A, Sato Y, Lie PP, Mohan P, Coffey EE, Kompella U, Mitchell CH, Lloyd-Evans E, Nixon RA (2015) Presenilin 1 Maintains Lysosomal $\mathrm{Ca}(2+)$ Homeostasis via TRPML1 by Regulating vATPase-Mediated Lysosome Acidification. Cell Report 12, 1430-1444.

[21] Heilig EA, Gutti U, Tai T, Shen J, Kelleher RJ, 3rd (2013) Trans-dominant negative effects of pathogenic PSEN1 mutations on $\gamma$-secretase activity and $A \beta$ production. $J$ Neurosci 33, 11606-11617.

[22] Schroeter EH, Ilagan MXG, Brunkan AL, Hecimovic S, Li Y-m, Xu M, Lewis HD, Saxena MT, De Strooper B, Coonrod A, Tomita T, Iwatsubo T, Moore CL, Goate A, Wolfe MS, Shearman M, Kopan R (2003) A presenilin dimer at the core of the $\gamma$-secretase enzyme: Insights from parallel analysis of Notch 1 and APP proteolysis. Proceedings of the National Academy of Sciences 100, 13075.

[23] Brautigam H, Moreno CL, Steele JW, Bogush A, Dickstein DL, Kwok JBJ, Schofield PR, Thinakaran G, Mathews PM, Hof PR, Gandy S, Ehrlich ME (2015) Physiologically generated presenilin 1 lacking exon 8 fails to rescue brain PS1-/- phenotype and forms complexes with wildtype PS1 and nicastrin. Scientific Reports 5, 17042.

[24] Li X, Dang S, Yan C, Gong X, Wang J, Shi Y (2013) Structure of a presenilin family intramembrane aspartate protease. Nature 493, 56-61.

[25] De Gasperi R, Sosa MAG, Dracheva S, Elder GA (2010) Presenilin-1 regulates induction of hypoxia inducible factor-1 $\alpha$ : altered activation by a mutation associated with familial Alzheimer's disease. Molecular Neurodegeneration 5, 38-38.

[26] Villa JC, Chiu D, Brandes AH, Escorcia FE, Villa CH, Maguire WF, Hu CJ, de Stanchina E, Simon MC, Sisodia SS, Scheinberg DA, Li YM (2014) Nontranscriptional role of Hif1alpha in activation of gamma-secretase and notch signaling in breast cancer. Cell Replication 8, 1077-1092.

[27] Newman M, Nik HM, Sutherland GT, Hin N, Kim WS, Halliday GM, Jayadev S, Smith C, Laird AS, Lucas CW, Kittipassorn T, Peet DJ, Lardelli M (2020) Accelerated loss of hypoxia response in zebrafish with familial Alzheimer's disease-like mutation of presenilin 1. Human Molecular Genetics 29, 2379-2394. 
[28] Lane DJR, Merlot AM, Huang MLH, Bae DH, Jansson PJ, Sahni S, Kalinowski DS, Richardson DR (2015) Cellular iron uptake, trafficking and metabolism: Key molecules and mechanisms and their roles in disease. Biochimica et Biophysica Acta (BBA) Molecular Cell Research 1853, 1130-1144.

[29] Güner G, Lichtenthaler SF (2020) The substrate repertoire of $\gamma$-secretase/presenilin. Seminars in Cell \& Developmental Biology 105, 27-42.

[30] Thinakaran G, Harris CL, Ratovitski T, Davenport F, Slunt HH, Price DL, Borchelt DR, Sisodia SS (1997) Evidence that levels of presenilins (PS1 and PS2) are coordinately regulated by competition for limiting cellular factors. J Biol Chem 272, 28415-28422.

[31] Berchtold NC, Sabbagh MN, Beach TG, Kim RC, Cribbs DH, Cotman CW (2014) Brain gene expression patterns differentiate mild cognitive impairment from normal aged and Alzheimer's disease. Neurobiology of Aging 35, 1961-1972.

[32] Villemagne VL, Burnham S, Bourgeat P, Brown B, Ellis KA, Salvado O, Szoeke C, Macaulay SL, Martins R, Maruff P, Ames D, Rowe CC, Masters CL (2013) Amyloid $\beta$ deposition, neurodegeneration, and cognitive decline in sporadic Alzheimer's disease: a prospective cohort study. The Lancet Neurology 12, 357-367.

[33] Foley AM, Ammar ZM, Lee RH, Mitchell CS (2015) Systematic review of the relationship between amyloid- $\beta$ levels and measures of transgenic mouse cognitive deficit in Alzheimer's disease. J Alzheimers Dis 44, 787-795.

[34] Hargis KE, Blalock EM (2017) Transcriptional signatures of brain aging and Alzheimer's disease: What are our rodent models telling us? Behavioural Brain Research 322, 311-328.

[35] Guo Q, Fu W, Sopher BL, Miller MW, Ware CB, Martin GM, Mattson MP (1999) Increased vulnerability of hippocampal neurons to excitotoxic necrosis in presenilin-1 mutant knock-in mice. Nat Med 5, 101-106.

[36] Kawasumi M, Chiba T, Yamada M, Miyamae-Kaneko M, Matsuoka M, Nakahara J, Tomita T, Iwatsubo T, Kato S, Aiso S, Nishimoto I, Kouyama K (2004) Targeted introduction of V642I mutation in amyloid precursor protein gene causes functional abnormality resembling early stage of Alzheimer's disease in aged mice. Eur J Neurosci 19, 2826-2838.

[37] Xu J, Burgoyne PS, Arnold AP (2002) Sex differences in sex chromosome gene expression in mouse brain. Human Molecular Genetics 11, 1409-1419. 
[38] Bundy JL, Vied C, Nowakowski RS (2017) Sex differences in the molecular signature of the developing mouse hippocampus. BMC Genomics 18, 237.

[39] Barthelson K, Pederson S, Newman M, Lardelli M (2020) Transcriptome analysis of a protein-truncating mutation in sortilin-related receptor 1 associated with early-onset familial Alzheimer's disease indicates effects on mitochondrial and ribosome function in young-adult zebrafish brains. bioRxiv, 2020.2009.2003.282277.

[40] Barthelson K, Pederson SM, Newman M, Jiang H, Lardelli M (2020) Frameshift and frame-preserving mutations in zebrafish presenilin 2 affect different cellular functions in young adult brains. bioRxiv, 2020.2011.2021.392761.

[41] Barthelson K, Pederson SM, Newman M, Lardelli M (2020) Brain transcriptome analysis reveals subtle effects on mitochondrial function and iron homeostasis of mutations in the SORL1 gene implicated in early onset familial Alzheimer's disease. Molecular Brain 13, 142.

[42] Hin N, Newman M, Kaslin J, Douek AM, Lumsden A, Nik SHM, Dong Y, Zhou X-F, Mañucat-Tan NB, Ludington A, Adelson DL, Pederson S, Lardelli M (2020) Accelerated brain aging towards transcriptional inversion in a zebrafish model of the K115fs mutation of human PSEN2. PLOS ONE 15, e0227258.

[43] Jiang H, Pederson SM, Newman M, Dong Y, Barthelson K, Lardelli M (2020) Transcriptome analysis indicates dominant effects on ribosome and mitochondrial function of a premature termination codon mutation in the zebrafish gene psen2. PLOS ONE 15, e0232559.

[44] Dong Y, Newman M, Pederson S, Hin N, Lardelli M (2020) Transcriptome analyses of 7-day-old zebrafish larvae possessing a familial Alzheimer's disease-like mutation in psen 1 indicate effects on oxidative phosphorylation, $\mathrm{mcm}$ functions, and iron homeostasis. bioRxiv, 2020.2005.2003.075424.

[45] Hin N, Newman M, Pederson SM, Lardelli MM (2020) Iron Responsive Element (IRE)mediated responses to iron dyshomeostasis in Alzheimer's disease. bioRxiv, 2020.2005.2001.071498.

[46] Newman M, Hin N, Pederson S, Lardelli M (2019) Brain transcriptome analysis of a familial Alzheimer's disease-like mutation in the zebrafish presenilin 1 gene implies effects on energy production. Molecular Brain 12. 
[47] Ishikawa A, Piao Y-S, Miyashita A, Kuwano R, Onodera O, Ohtake H, Suzuki M, Nishizawa M, Takahashi H (2005) A mutant PSEN1 causes dementia with lewy bodies and variant Alzheimer's disease. Annals of Neurology 57, 429-434.

[48] Zhang Y, Zhang Z, Ge W (2018) An efficient platform for generating somatic point mutations with germline transmission in the zebrafish by CRISPR/Cas9-mediated gene editing. J Biol Chem 293, 6611-6622.

[49] Prykhozhij SV, Fuller C, Steele SL, Veinotte CJ, Razaghi B, Robitaille JM, McMaster CR, Shlien A, Malkin D, Berman JN (2018) Optimized knock-in of point mutations in zebrafish using CRISPR/Cas9. Nucleic Acids Research 46, e102-e102.

[50] Jiang H, Newman M, Lardelli M (2018) The zebrafish orthologue of familial Alzheimer's disease gene PRESENILIN 2 is required for normal adult melanotic skin pigmentation. PLOS ONE 13, e0206155.

[51] Di Tommaso P, Chatzou M, Floden EW, Barja PP, Palumbo E, Notredame C (2017) Nextflow enables reproducible computational workflows. Nature Biotechnology 35, 316-319.

[52] Team RC (2019) R: A language and environment for statistical computing. $R$ Foundation for Statistical Computing, Vienna, Austria.

[53] Chen Y, Lun A, Smyth G (2016) From reads to genes to pathways: differential expression analysis of RNA-Seq experiments using Rsubread and the edgeR quasilikelihood pipeline [version 2; peer review: 5 approved]. F1000Research 5.

[54] Robinson MD, Oshlack A (2010) A scaling normalization method for differential expression analysis of RNA-seq data. Genome Biology 11, R25.

[55] McCarthy DJ, Chen Y, Smyth GK (2012) Differential expression analysis of multifactor RNA-Seq experiments with respect to biological variation. Nucleic Acids Research 40, 4288-4297.

[56] Robinson MD, McCarthy DJ, Smyth GK (2009) edgeR: a Bioconductor package for differential expression analysis of digital gene expression data. Bioinformatics 26, 139-140.

[57] Young MD, Wakefield MJ, Smyth GK, Oshlack A (2010) Gene ontology analysis for RNA-seq: accounting for selection bias. Genome Biology 11, R14. 
[58] Wu D, Lim E, Vaillant F, Asselin-Labat M-L, Visvader JE, Smyth GK (2010) ROAST: rotation gene set tests for complex microarray experiments. Bioinformatics 26, 21762182.

[59] Wu D, Smyth GK (2012) Camera: a competitive gene set test accounting for intergene correlation. Nucleic acids research 40, e133-e133.

[60] Sergushichev AA (2016) An algorithm for fast preranked gene set enrichment analysis using cumulative statistic calculation. bioRxiv, 060012.

[61] Subramanian A, Tamayo P, Mootha VK, Mukherjee S, Ebert BL, Gillette MA, Paulovich A, Pomeroy SL, Golub TR, Lander ES, Mesirov JP (2005) Gene set enrichment analysis: A knowledge-based approach for interpreting genome-wide expression profiles. Proceedings of the National Academy of Sciences 102, 15545.

[62] Kanehisa M, Goto S (2000) KEGG: kyoto encyclopedia of genes and genomes. Nucleic acids research $28,27-30$.

[63] Liberzon A (2014) A description of the Molecular Signatures Database (MSigDB) Web site. Methods Mol Biol 1150, 153-160.

[64] Dolgalev I (2020), p. R package.

[65] Chen X (2011) Adaptive elastic-net sparse principal component analysis for pathway association testing. Statistical applications in genetics and molecular biology 10, 48.

[66] Odom GJ, Ban Y, Liu L, Sun X, Pico AR, Zhang B, Wang L, Chen X (2019) pathwayPCA: an $\mathrm{R}$ package for integrative pathway analysis with modern PCA methodology and gene selection. bioRxiv, 615435 .

[67] Liberzon A, Birger C, Thorvaldsdóttir H, Ghandi M, Mesirov Jill P, Tamayo P (2015) The Molecular Signatures Database Hallmark Gene Set Collection. Cell Systems 1, 417-425.

[68] Kosik KS, Muñoz C, Lopez L, Arcila ML, García G, Madrigal L, Moreno S, Ríos Romenets S, Lopez H, Gutierrez M, Langbaum JB, Cho W, Suliman S, Tariot PN, Ho C, Reiman EM, Lopera $F$ (2015) Homozygosity of the autosomal dominant Alzheimer disease presenilin 1 E280A mutation. Neurology 84, 206-208. 
880

881

882

883

884

885

886

887

888

889

890

891

892

[69] Parker J, Mozaffar T, Messmore A, Deignan JL, Kimonis VE, Ringman JM (2019) Homozygosity for the A431E mutation in PSEN1 presenting with a relatively aggressive phenotype. Neurosci Lett 699, 195-198.

[70] Sundvik M, Chen Y-C, Panula P (2013) Presenilin1 Regulates Histamine Neuron Development and Behavior in Zebrafish, \&lt;em\&gt;Danio rerio\&lt;/em\&gt. The Journal of Neuroscience 33, 1589.

[71] Tambini MD, D'Adamio L (2020) Knock-in rats with homozygous PSEN1(L435F) Alzheimer mutation are viable and show selective $\gamma$-secretase activity loss causing low $A \beta 40 / 42$ and high $A \beta 43$. J Biol Chem 295, 7442-7451.

[72] Xia D, Watanabe H, Wu B, Lee SH, Li Y, Tsvetkov E, Bolshakov VY, Shen J, Kelleher RJ, 3rd (2015) Presenilin-1 knockin mice reveal loss-of-function mechanism for familial Alzheimer's disease. Neuron 85, 967-981.

[73] Nickless A, Bailis JM, You Z (2017) Control of gene expression through the nonsensemediated RNA decay pathway. Cell \& Bioscience 7, 26.

[74] Alhamdoosh M, Law CW, Tian L, Sheridan JM, Ng M, Ritchie ME (2017) Easy and efficient ensemble gene set testing with EGSEA. F1000Research 6, 2010-2010.

[75] Wilson DJ (2019) The harmonic mean p-value for combining dependent tests. Proceedings of the National Academy of Sciences 116, 1195.

[76] Pan Y, Lin MH, Tian X, Cheng HT, Gridley T, Shen J, Kopan R (2004) gamma-secretase functions through Notch signaling to maintain skin appendages but is not required for their patterning or initial morphogenesis. Dev Cell 7, 731-743.

[77] Blanpain C, Lowry WE, Pasolli HA, Fuchs E (2006) Canonical notch signaling functions as a commitment switch in the epidermal lineage. Genes Dev 20, 3022-3035.

[78] Kopan R, llagan MX (2009) The canonical Notch signaling pathway: unfolding the activation mechanism. Cell 137, 216-233.

[79] Nowell C, Radtke F (2013) Cutaneous Notch signaling in health and disease. Cold Spring Harbor perspectives in medicine 3, a017772-a017772.

[80] Nguyen B-C, Lefort K, Mandinova A, Antonini D, Devgan V, Della Gatta G, Koster MI, Zhang Z, Wang J, di Vignano AT, Kitajewski J, Chiorino G, Roop DR, Missero C, Dotto 
GP (2006) Cross-regulation between Notch and p63 in keratinocyte commitment to differentiation. Genes \& Development 20, 1028-1042.

[81] Dohda T, Maljukova A, Liu L, Heyman M, Grandér D, Brodin D, Sangfelt O, Lendahl U (2007) Notch signaling induces SKP2 expression and promotes reduction of p27Kip1 in T-cell acute lymphoblastic leukemia cell lines. Exp Cell Res 313, 3141-3152.

[82] Ryan RJH, Petrovic J, Rausch DM, Zhou Y, Lareau CA, Kluk MJ, Christie AL, Lee WY, Tarjan DR, Guo B, Donohue LKH, Gillespie SM, Nardi V, Hochberg EP, Blacklow SC, Weinstock DM, Faryabi RB, Bernstein BE, Aster JC, Pear WS (2017) A B Cell Regulome Links Notch to Downstream Oncogenic Pathways in Small B Cell Lymphomas. Cell Rep 21, 784-797.

[83] El-Brolosy MA, Kontarakis Z, Rossi A, Kuenne C, Günther S, Fukuda N, Kikhi K, Boezio GLM, Takacs CM, Lai S-L, Fukuda R, Gerri C, Giraldez AJ, Stainier DYR (2019) Genetic compensation triggered by mutant mRNA degradation. Nature 568, 193-197.

[84] Rossi A, Kontarakis Z, Gerri C, Nolte H, Hölper S, Krüger M, Stainier DYR (2015) Genetic compensation induced by deleterious mutations but not gene knockdowns. Nature 524, 230-233.

[85] Luo W, Pant G, Bhavnasi YK, Blanchard SG, Jr., Brouwer C (2017) Pathview Web: user friendly pathway visualization and data integration. Nucleic Acids Research 45, W501W508.

[86] Ryman DC, Acosta-Baena N, Aisen PS, Bird T, Danek A, Fox NC, Goate A, Frommelt P, Ghetti B, Langbaum JBS, Lopera F, Martins R, Masters CL, Mayeux RP, McDade E, Moreno S, Reiman EM, Ringman JM, Salloway S, Schofield PR, Sperling R, Tariot PN, Xiong C, Morris JC, Bateman RJ (2014) Symptom onset in autosomal dominant Alzheimer disease: A systematic review and meta-analysis. Neurology 83, 253-260.

[87] Oksanen M, Petersen AJ, Naumenko N, Puttonen K, Lehtonen Š, Gubert Olivé M, Shakirzyanova A, Leskelä S, Sarajärvi T, Viitanen M, Rinne JO, Hiltunen M, Haapasalo A, Giniatullin R, Tavi P, Zhang S-C, Kanninen KM, Hämäläinen RH, Koistinaho J (2017) PSEN1 Mutant iPSC-Derived Model Reveals Severe Astrocyte Pathology in Alzheimer's Disease. Stem Cell Reports 9, 1885-1897.

[88] Martín-Maestro P, Sproul A, Martinez H, Paquet D, Gerges M, Noggle S, Starkov AA (2019) Autophagy Induction by Bexarotene Promotes Mitophagy in Presenilin 1 Familial Alzheimer's Disease iPSC-Derived Neural Stem Cells. Molecular Neurobiology 56, 8220-8236. 
930

931

932

933

934

935

936

937

938

939

940

941

942

943

944

945

946

947

948

949

950

951

952

953

954

955

956

957

958

959

960

[89] Birnbaum JH, Wanner D, Gietl AF, Saake A, Kündig TM, Hock C, Nitsch RM, Tackenberg $C$ (2018) Oxidative stress and altered mitochondrial protein expression in the absence of amyloid- $\beta$ and tau pathology in iPSC-derived neurons from sporadic Alzheimer's disease patients. Stem Cell Res 27, 121-130.

[90] Kwart D, Gregg A, Scheckel C, Murphy EA, Paquet D, Duffield M, Fak J, Olsen O, Darnell RB, Tessier-Lavigne M (2019) A Large Panel of Isogenic APP and PSEN1 Mutant Human iPSC Neurons Reveals Shared Endosomal Abnormalities Mediated by APP $\beta$-CTFs, Not A . Neuron 104, 256-270.e255.

[91] Volpato V, Smith J, Sandor C, Ried JS, Baud A, Handel A, Newey SE, Wessely F, Attar M, Whiteley E, Chintawar S, Verheyen A, Barta T, Lako M, Armstrong L, Muschet C, Artati A, Cusulin C, Christensen K, Patsch C, Sharma E, Nicod J, Brownjohn P, Stubbs V, Heywood WE, Gissen P, De Filippis R, Janssen K, Reinhardt P, Adamski J, Royaux I, Peeters PJ, Terstappen GC, Graf M, Livesey FJ, Akerman CJ, Mills K, Bowden R, Nicholson G, Webber C, Cader MZ, Lakics V (2018) Reproducibility of Molecular Phenotypes after Long-Term Differentiation to Human iPSC-Derived Neurons: A Multi-Site Omics Study. Stem Cell Reports 11, 897-911.

[92] Hunger RE, Surovy AM, Hassan AS, Braathen LR, Yawalkar N (2008) Toll-like receptor 2 is highly expressed in lesions of acne inversa and colocalizes with C-type lectin receptor. British Journal of Dermatology 158, 691-697.

[93] Otani K, Shichita T (2020) Cerebral sterile inflammation in neurodegenerative diseases. Inflammation and Regeneration 40, 28.

[94] Zouboulis CC, Benhadou F, Byrd AS, Chandran NS, Giamarellos-Bourboulis EJ, Fabbrocini G, Frew JW, Fujita H, González-López MA, Guillem P, Gulliver WPF, Hamzavi I, Hayran $Y$, Hórvath $B$, Hüe $S$, Hunger RE, Ingram JR, Jemec GBE, Ju Q, Kimball AB, Kirby JS, Konstantinou MP, Lowes MA, MacLeod AS, Martorell A, Marzano AV, Matusiak $Ł$, Nassif A, Nikiphorou E, Nikolakis G, Nogueira da Costa A, Okun MM, Orenstein LAV, Pascual JC, Paus R, Perin B, Prens EP, Röhn TA, Szegedi A, Szepietowski JC, Tzellos T, Wang B, van der Zee HH (2020) What causes hidradenitis suppurativa ?-15 years after. Experimental Dermatology 29, 1154-1170.

[95] Research loMUCoMN (1999) The Energy Costs of Protein Metabolism: Lean and Mean on Uncle Sam's Team In The Role of Protein and Amino Acids in Sustaining and Enhancing Performance National Academies Press (US), Washington (DC).

[96] Bordi M, Darji S, Sato Y, Mellén M, Berg MJ, Kumar A, Jiang Y, Nixon RA (2019) mTOR hyperactivation in Down Syndrome underlies deficits in autophagy induction, autophagosome formation, and mitophagy. Cell Death \& Disease 10, 563. 
[97] Jiang Y, Sato Y, Im E, Berg M, Bordi M, Darji S, Kumar A, Mohan PS, Bandyopadhyay U, Diaz A, Cuervo AM, Nixon RA (2019) Lysosomal Dysfunction in Down Syndrome Is APP-Dependent and Mediated by APP-BCTF (C99). The Journal of Neuroscience 39, 5255.

[98] Lee JH, Yu WH, Kumar A, Lee S, Mohan PS, Peterhoff CM, Wolfe DM, MartinezVicente M, Massey AC, Sovak G, Uchiyama Y, Westaway D, Cuervo AM, Nixon RA (2010) Lysosomal proteolysis and autophagy require presenilin 1 and are disrupted by Alzheimer-related PS1 mutations. Cell 141, 1146-1158.

[99] Linke M, Fritsch SD, Sukhbaatar N, Hengstschläger M, Weichhart T (2017) mTORC1 and mTORC2 as regulators of cell metabolism in immunity. FEBS letters 591, 30893103.

[100] Inpanathan S, Botelho RJ (2019) The Lysosome Signaling Platform: Adapting With the Times. Frontiers in Cell and Developmental Biology 7, 113.

[101] Bond P (2016) Regulation of mTORC1 by growth factors, energy status, amino acids and mechanical stimuli at a glance. J Int Soc Sports Nutr 13, 8.

[102] Loewith R, Hall MN (2011) Target of rapamycin (TOR) in nutrient signaling and growth control. Genetics 189, 1177-1201.

[103] Lempiäinen H, Shore D (2009) Growth control and ribosome biogenesis. Current Opinion in Cell Biology 21, 855-863.

[104] Newman M, Wilson L, Verdile G, Lim A, Khan I, Moussavi Nik SH, Pursglove S, Chapman G, Martins RN, Lardelli M (2014) Differential, dominant activation and inhibition of Notch signalling and APP cleavage by truncations of PSEN1 in human disease. Human Molecular Genetics 23, 602-617.

[105] Kelleher RJ, Shen J (2017) Presenilin-1 mutations and Alzheimer's disease. Proceedings of the National Academy of Sciences 114, 629.

[106] Zhou R, Yang G, Shi Y (2017) Dominant negative effect of the loss-of-function $\gamma$ secretase mutants on the wild-type enzyme through heterooligomerization. Proc Natl Acad Sci U S A 114, 12731-12736.

[107] Chávez-Gutiérrez L, Bammens L, Benilova I, Vandersteen A, Benurwar M, Borgers $M$, Lismont S, Zhou L, Van Cleynenbreugel S, Esselmann H, Wiltfang J, Serneels L, Karran E, Gijsen H, Schymkowitz J, Rousseau F, Broersen K, De Strooper B (2012) The 
mechanism of $\gamma$-Secretase dysfunction in familial Alzheimer disease. The EMBO

Journal 31, 2261-2274.

994

995

996

997

998

999

1000

1001

1002

1003

1004

[108] Zhang S, Cai F, Wu Y, Bozorgmehr T, Wang Z, Zhang S, Huang D, Guo J, Shen L, Rankin C, Tang B, Song W (2020) A presenilin-1 mutation causes Alzheimer disease without affecting Notch signaling. Molecular Psychiatry 25, 603-613.

[109] Deatherage CL, Lu Z, Kroncke BM, Ma S, Smith JA, Voehler MW, McFeeters RL, Sanders CR (2017) Structural and biochemical differences between the Notch and the amyloid precursor protein transmembrane domains. Science Advances 3, e1602794.

[110] Bukhari H, Glotzbach A, Kolbe K, Leonhardt G, Loosse C, Müller T (2017) Small things matter: Implications of APP intracellular domain AICD nuclear signaling in the progression and pathogenesis of Alzheimer's disease. Progress in Neurobiology 156, 189-213. 